\title{
CFD Applied to Process Development in the Oil and Gas Industry - A Review
}

\author{
L. Raynal*, F. Augier, F. Bazer-Bachi, Y. Haroun and C. Pereira da Fonte \\ IFP Energies nouvelles, Rond-point de l'échangeur de Solaize, BP 3, 69360 Solaize - France \\ e-mail: ludovic.raynal@ifpen.fr - frederic.augier@ifpen.fr - frederic.bazer-bachi@ifpen.fr \\ yacine.haroun@ifpen.fr - claudio.fonte@ifpen.fr \\ * Corresponding author
}

\begin{abstract}
Computational Fluid Dynamics (CFD) is increasingly used in the oil and gas industry. The present article aims to show how CFD can be used at all steps of the development of a new process, with a focus on refining technologies. Those different steps consist first of setting up tools that will be used during the development phase, second of obtaining data in complement with experiments required for the process development, and finally, of troubleshooting actions or technology developments that will make the process even more efficient. A large number of applications corresponding to various flow configurations, single-phase or gas-liquid, gas-solid or even gas-liquid-solid, characterised by significantly different scales and requiring adapted simulation approaches, are discussed based on original results and a review of the literature. Perspectives are given in particular on the multi-scale approach and physical phenomena coupling.
\end{abstract}

Résumé - La simulation numérique des écoulements appliquée au développement de procédés dans le monde de l'industrie du pétrole et du gaz - une revue - La simulation numérique des écoulements, ou Computational Fluid Dynamics (CFD), est un outil de plus en plus employé dans les secteurs pétrolier et gazier. Cet article permet d'illustrer comment l'outil numérique est utilisé lors des différents stades de développement d'un nouveau procédé, en particulier dans le monde du raffinage. Ces différentes phases correspondent tout d'abord à la mise au point des équipements qui seront utilisés pour le développement, puis au complément des essais lors de la phase de développement proprement dite et enfin à des actions support pour la résolution de problèmes opératoires ou l'amélioration de technologies qui permettront d'optimiser le procédé. De nombreuses applications correspondant à différents types d'écoulements, monophasique ou gaz-liquide, gazsolide et gaz-liquide-solide, caractérisées par des échelles de résolution différentes et requérant des approches de simulations adaptées sont discutées sur la base de résultats originaux et d'une revue de travaux déjà publiés. Des perspectives sont aussi données tant sur les aspects approche multi-échelles que sur le couplage de phénomènes. 


\section{ACRONYMS}

$\begin{array}{ll}\text { CAD } & \text { Computer-Aided Design } \\ \text { CCR } & \text { Continuous Catalytic Reforming } \\ \text { CDU } & \text { Crude Distillation Unit } \\ \text { CFD } & \text { Computational Fluid Dynamics } \\ \text { CPU } & \text { Central Processing Unit } \\ \text { CR } & \text { Catalytic Reforming } \\ \text { DNS } & \text { Direct Numerical Simulation } \\ \text { FCC } & \text { Fluid Catalytic Cracking } \\ \text { FT } & \text { Fischer-Tropsch } \\ \text { GPU } & \text { Graphics Processing Unit } \\ \text { HCK } & \text { HydroCracKing } \\ \text { HDS } & \text { HydroDeSulphurisation unit } \\ \text { HDT } & \text { HyDroTreating unit } \\ \text { LES } & \text { Large-Eddy Simulations } \\ \text { MEA } & \text { MonoEthanolAmine } \\ \text { MDEA } & \text { Methyl-DiEthanolAmine } \\ \text { MRF } & \text { Multiple Reference Frame } \\ \text { PIV } & \text { Particle Image Velocimetry } \\ \text { RANS } & \text { Reynolds Averaged Navier-Stokes } \\ \text { SGS } & \text { SubGrid Scale } \\ \text { TBR } & \text { Trickle-Bed Reactor } \\ \text { VDU } & \text { Vacuum Distillation Unit } \\ \text { VOF } & \text { Volume Of Fluid }\end{array}$

\section{INTRODUCTION}

Computational Fluid Dynamics (CFD) has been used more and more in the oil and gas industry since the 90s for many purposes. Indeed, since the original expectations of Trambouze (1993) and one of the first reviews on the subject (Kuipers and van Swaaij, 1997), one can see from Figure 1 that the number of scientific papers concerning CFD and chemical reaction engineering is booming. This figure is based on research performed on the World of Science core collection by Thomson Reuters on Nov. 28th 2014. It shows the number of papers containing the word CFD and another keyword (chemical engineering, technology development or process development) in the topic over periods of 5 years. From this, and whatever the keyword used in addition to CFD, it can be considered that the early 90 s correspond to the dawn of CFD in chemical reaction engineering, and the late 90 s show a real start, the boom being obvious in the 2000s.

CFD is first used to complement experimental data for obtaining results either experimentally difficult to obtain or deduced from sensitivity studies that would be time-consuming experimentally. The objective here is to

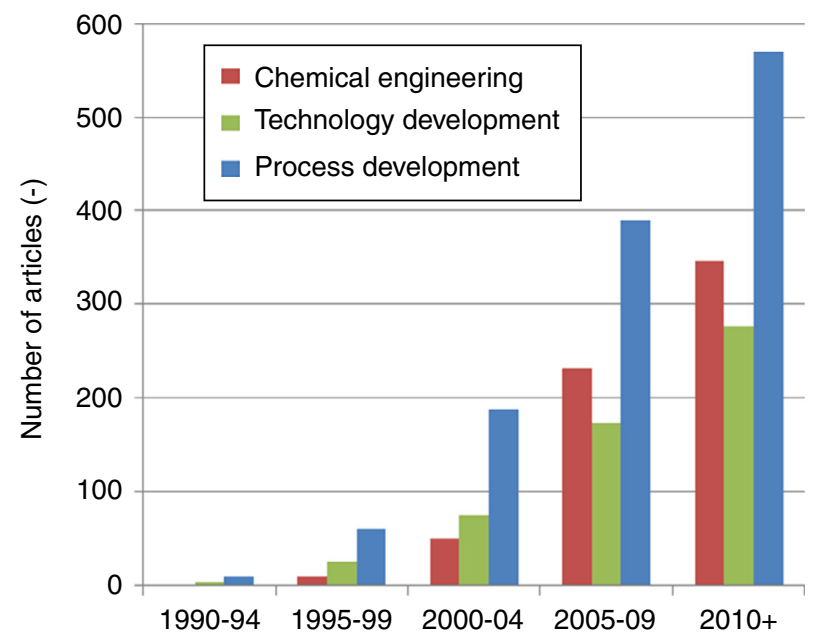

Figure 1

Time evolution of the number of articles including CFD and various keywords in the topic.

develop a better comprehension of physical phenomena and to provide further understanding of what happens in chemical reactors. It is also used for designing equipment which has to be linked with Computer-Aided Design (CAD) use in the mechanical industry. More recently, it has been considered as an efficient tool to be used before performing any experiments and of great help for designing the corresponding experimental set-ups. CFD is thus applied at all steps of process development and the present paper aims to illustrate it with an original approach proposing an analogy between process development steps and CFD calculation steps in the particular framework of the oil and gas sector.

The first step in CFD modeling is called pre-processing. It consists of setting up the case, defining the geometry and most importantly, since it is less visible, choosing the adequate boundary conditions and the appropriate mesh. With the increasing Central Processing Unit (CPU) performances and some novel meshing approaches, young research engineers tend to pay less attention to the mesh quality. However, it is well known that a carefully prepared mesh with low skewness factor cells and oriented in the main flow direction will contribute to a more efficient convergence, and that minimum numbers of cells are required in zones with high shear. Boundary condition choice is of even greater importance since it gives the physical meanings to the calculations. The choice is often not obvious since the flow characteristics at inlets (phase distributions, particle sizes, pressure, etc.) are not always well known. They can thus be the subject of sensitivity analysis during the calculation step. Concerning the process development, this step 
consists of the definition of the tools that will be used for laboratory elementary studies or during the pilot test phase. For example, if one develops a new catalyst material or a new catalytic process, the development and catalyst screening phase would probably be performed on tools with hydrodynamics that significantly differ from those encountered in industrial catalytic reactors. One has consequently to make sure that what will be obtained on the screening tool is meaningful and that there is no artifact, such as a gas-liquid mass transfer limitation, for example, that will affect the catalytic performances. As another example, if one wants to develop masstransfer relationships in a trickle-bed reactor, one must be sure that the column used for the test is large enough so that wall effects are negligible. Thus, this pre-processing step is the period of time in which one has to invest to make the real development phase more efficient, and it is sometimes neglected.

Step 2 consists of the calculations themselves, which corresponds, in the present analogy, to the process development step. This is the hard part, concentrating most of the work. In CFD simulations, appropriate models (in terms of physical modeling and mathematical solvers) will have to be chosen. Calculations will be performed directly or via a multiscale approach so as to develop better understanding and physical correlations that could be used in process flow sheet simulations or in process design rules. CFD is used as a complementary tool to experiments which require appropriate sensors and can be performed on a laboratory scale or on a large pilot scale. The purpose of step 2 is to develop the appropriate knowledge to design the chemical reactors, and especially the reactive section, and further bring corresponding innovations to the market.

The third step in CFD modeling is called post-processing or post-treatment. It consists of making the most of the calculations; it can either be used to show colourful illustrations or provide quantitative information that would increase the value of simulations. Concerning the process development, the analogy would correspond to diagnostics, troubleshooting or equipment design. The main objective is a better design and optimised technologies, making the flow as ideal as possible for achieving the desired yields or performances.

This article presents original work and already published results which illustrate these different steps with examples almost all taken from the oil refining industry. Simulations of refining chemical reactors are indeed quite challenging. The range of scales from the reactor main dimensions to the thickness of the liquid diffusion layer on the catalyst is about $10^{6}$ orders of magnitude. In most cases, one has to deal with very complex and unstable multi-phase flows with extreme operating conditions, not always resulting in wellknown physical properties and, last but not least, many physical phenomena are involved and coupled with each other: fluid mechanics with strong gas/liquid/solid multi-phase interactions, mass and heat transfer and chemical reactions.
As a result, a full CFD simulation of a process is impossible, and may still remain impossible for some years to come, whatever the progress of CPU or GPU computing may be. Simplification is thus required; either by decoupling phenomena or by considering a multi-scale strategy combining different simulations on different scales, and often by doing both.

The following section describes the main refining processes and associated simulation approaches that are considered further in the paper. Section 2 provides examples of CFD use for pre-processing/pre-development studies. Development and post-development case studies are respectively discussed in Sections 3 and 4. The paper ends with a conclusion and tries to show some perspectives in terms of both CFD development and CFD use.

\section{REFINING PROCESSES AND CFD APPROACHES}

\subsection{Refining Processes and Associated Flow Conditions}

Crude oil is a very complex mixture of thousands of compounds which need to be separated, upgraded and eventually rearranged before being transformed into valuable products, mostly as intermediate products for the petrochemical industry or final products for the automotive and transportation industry. Petroleum refining is thus based on a smart combination of separation and reactive processes to yield various valuable products which have to comply with more and more severe specifications.

Figure 2 shows a simplified block flow diagram of a typical refinery. Crude oil enters the Crude Distillation Unit (CDU), which consists of an atmospheric distillation column in which vapour and liquid flow countercurrently through internals. Usually, five products are generated from the CDU; namely gas, naphtha, which is usually further split into light and heavy naphtha, kerosene or jet fuel, light straight run gas oil, and the atmospheric residue being further split in the Vacuum Distillation Unit (VDU) into a vacuum gas oil and a vacuum residue. Distillation is sometimes considered of less importance than reactive processes since it does not directly contribute to the heart of the process, that is the expected chemical transformation. However, it is a key elementary separation operation without which the standard distillation scheme would not be operational. Besides, it is interesting to note that, in refineries, distillation columns are far more numerous than reactor vessels. Optimisation of distillation columns can thus significantly contribute to refinery optimisation. Distillation columns are either equipped with trays, or random or structured packings. Packings have become more and more popular, in particular since they offer significant pressure loss reduction. However, for most column diameters, trays are considered of lower 


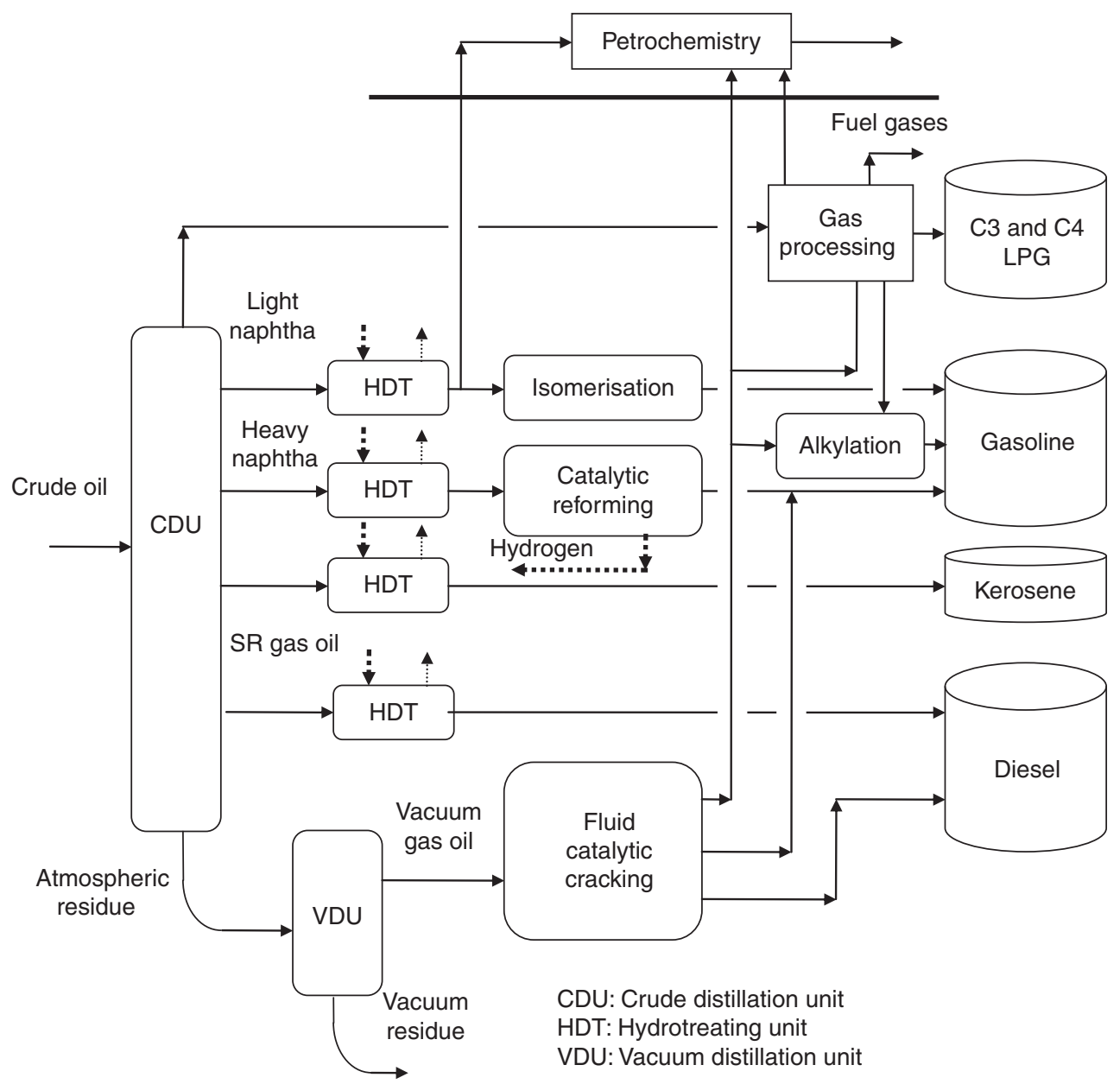

Figure 2

Simplified refining block flow diagram.

cost than packings and, in the case of high-pressure operation (above 6-10 bar), they still offer good separation efficiency while back-mixing may be encountered with packings, further resulting in column efficiency drop and distillation failure. Trays are still of high importance; CFD application to this type of internal is discussed in Section 3.1. Gas-liquid flow in packings has also been investigated, on different scales either for closure law developments, in particular for liquid-side mass transfer parameters, or for pressure drop determination (Haroun et al., 2010; Petre et al., 2003), for studies on a large scale, in particular for distribution device development and liquid dispersion description (Raynal et al., 2013; Fourati et al., 2013), and even for packing geometry optimisation (Luo S.J. et al., 2008). No further details on this type of flow are given in the present paper since it is discussed by Haroun and Raynal (2015).

Most products coming out from the CDU contain impurities, such as sulphur or nitrogen, and need to be hydrotreated.
This process operation, represented here as a HyDroTreating unit (HDT), involves fixed-bed reactors with catalysts with the shape of spherical particles and most often of extrudates, a few millimetres in diameter (typically trilobes of 1.2-2.5 mm in diameter). Depending on the operating conditions and the range of boiling temperatures of the oil cuts considered, single or two-phase flows are present in the reactors. In the last case, various hydrodynamic behaviours are possible, namely trickling, bubbles, and pulsed or atomising regimes ( $\mathrm{Ng}$ and $\mathrm{Chu}, 1987)$. However, in practice, two types of fixed-bed reactors are frequently encountered in a refinery: single-phase gas flows and mainly liquid-gas trickling flows. Bubbly flow regimes in fixed-bed reactors are specifically involved in the case of selective hydrogenation units of steam-cracking products, not discussed in the present paper.

Among the most important processes shown in Figure 2, it is interesting to focus on Catalytic Reforming (CR) and Fluid Catalytic Cracking (FCC), which operate with 
continuous catalyst regeneration and with two very different gas/solid flows. CR is a key refining process whose principal aims are first to transform the naphtha feed into a highoctane reformate for gasoline blending, second to produce high-value aromatics for the petrochemical industry, and finally, to produce hydrogen, a high-value by-product which is used in other processes, in particular in the HDT described above (Antos and Aitani, 2004). The latest technology, called Continuous Catalytic Reforming (CCR), consists of several radial moving bed reactors mounted in series, preceded by furnaces to compensate for the reactions' endothermy, the whole being in connection with a continuous in situ regenerator. In each capacity, the millimetric catalyst flows downwards by gravity (velocity $\sim 10^{-4} \mathrm{~m} \cdot \mathrm{s}^{-1}$ ), while gas naphtha feed flows radially inward (velocity $\sim \mathrm{m} . \mathrm{s}^{-1}$ ). FCC is a very complex process made of two reactor zones. In the riser, the heavy oil feedstock is introduced as a liquid, and is atomised and vaporised due to immediate contact with the high-temperature catalyst, in which it further cracks into lighter valuable products, in particular gasoline, but also propylene and diesel. The catalyst is made of solid particles $70 \mu \mathrm{m}$ in diameter which belong to group $\mathrm{A}$ in the Geldart classification; they thus behave as a fluid with strong solid/ solid interactions. The catalyst particles are continuously transported from the riser zone to the regenerator, a turbulent fluidised bed reactor where the coke formed during cracking is burnt with air. Once regenerated, it goes back to the riser. The solid entrainment is possible due to the high gas velocities in the riser, which can be up to $20 \mathrm{~m} \cdot \mathrm{s}^{-1}$.

In parallel to "standard refining", it is worth mentioning the development of the Fischer-Tropsch (FT) process, which, from synthesis gas, produces high-quality diesel and for which a slurry bubble column type of reactor is now considered as the preferred reactor technology (Dry, 2002). This catalytic process, initially developed for producing fuels from coal, has been extensively studied and further developed in the last 20 years. This can be explained in particular by the large reserves of coal and natural gas and the recent use of biomass, which are all growing carbon resources in competition with crude oil and which can be used in the gasification plant upstream of the FT unit. The advantage of the FT process is also the fact that it can provide high-quality diesel fuel with no sulphur, no aromatics and a high cetane number. Since the FT reactions are highly exothermic, it is important to efficiently remove the heat of reaction from the catalyst particles, which is in favour of a slurry reactor technology in comparison with multi-tubular fixed-bed technology. This has motivated the study of slurry bubble columns with the particular objective of extrapolation to very large-diameter columns in order to increase the capacity and reduce costs. The slurry bubble column is the technology used in the recent and huge FT plant in Qatar
(Oryx GTL, 2015). The simulation of bubble columns for FT development purposes is also discussed in Section 3.

\subsection{CFD Approaches}

The purpose of the present paper is not to describe CFD approaches that are used in the examples discussed hereafter. In all cases the required references where simulation details can be found are given. The idea is just to give a quick overview of the simulation approaches underlining the possibility they offer.

With a classification from the less to the more complex flow, one would first describe the case of the reforming process. As previously described, a significant difference in velocity exists in the radial gas and the axial solid flow. The consequence for CFD modeling is that the catalyst may be considered as an immobile material compared with the gas flow, at least if the CFD simulations do not focus on the interactions between the gas flow and catalyst that can provoke catalyst flow disturbances (Ginestra and Jackson, 1985). Depending on the objective, that is either being able to determine local gas flow and heat transfer properties, as performed e.g. by Nijemeisland and Dixon (2004), or determining flow behaviour at column scale, as discussed in Section 4.1, one would either consider a local approach with no assumption which can be considered as a Direct Numerical Simulation (DNS) limited to a few number of particles, or a porous-media approach, which makes simulation at column scale possible. In both cases, CFD simulations are thought to be an adequate tool from which quantitative results are expected.

In the case of distillation, once again, two approaches can be considered. The first one would focus on a local scale with a Volume Of Fluid (VOF) or similar approach, that is, an approach with no interpenetrating phases and calculation of the interface. This makes possible the study of the gas-liquid flow behaviour at an orifice. The second approach would consist of Euler/Euler simulations, that is, a macroscopic averaged approach considering phases as interpenetrating media with momentum equations containing interaction terms, the latter requiring adapted closure terms. As discussed in this article, these approaches can provide very interesting results with close agreement with experiments and are thus of great interest for extrapolation purposes. However, they require closure terms, which often result from complementary work not always performed in fully representative conditions.

For trickle-bed reactors, the gas/liquid/flow is even more complex. The gas/liquid flow is superimposed on a fixed bed and simulations must take into account the interactions with the solid in terms of momentum exchanges, but should also integrate reactant and product diffusion in the catalyst and consideration of reaction effects via heat sinks or sources. 
Due to this complexity, multi-scale approaches and decoupling phenomena must be considered. Local or global approaches are discussed in Section 3.2.

FCC is probably one of the most challenging processes to simulate. Feed atomization and vaporization, reaction and coke deposition, liquid/solid and strongly coupled group A solid particles/gas flow are all complex phenomena, each of them still being not well understood. On top of this, one has to consider a reaction scheme implying a huge number of chemical compounds, which has to be coupled with heat transfers and phase change between solid, gas and liquid. Once again, decoupling and simplification must be considered, which also means that results must be cautiously considered. One would thus conclude that qualitative trends only can be deduced from CFD simulations; however, this is still important, as discussed in Section 3.1.

In most cases, laminar and mostly Reynolds Averaged Navier-Stokes, (RANS) $k-\varepsilon$, turbulent models are respectively used for low or high Reynolds number flows. Since the flows considered are quite far from the well-known reference cases (homogeneous jet, mixing layer, wall boundary layer or wake flow), some model constants, and most frequently, the interaction terms are adapted or tuned via a validation step against experimental results. Note that the latter experiments are not always that representative, but at least they are close to what people want to simulate. The a priori more robust, for relying on less assumptions, Large-Eddy Simulations (LES) are scarcely used in chemical engineering. This can be explained by two main reasons. First, such an approach requires adapted SubGrid Scale (SGS) models, and most of them have been developed for fully turbulent homogeneous flow only and still require further development for two-phase flows; this is work in progress (Boivin et al., 2000; Deen et al., 2007). Second, this approach requires intensive CPU resources which are not always accessible in the industrial sector, and limit its use to the applied chemical engineering world.

In the following, examples, implying different types of modeling approaches, will be given for all steps encountered in process development.

\section{CFD FOR PRE-DEVELOPMENT STUDIES}

\subsection{Impeller Choice for Proper Stirring}

Before being adopted in an industrial process, the catalysts being developed for the refining and petrochemical industries must undergo a laboratory screening step in order to evaluate their intrinsic kinetics. It can either be done with powder or crushed catalyst or with the real shape catalyst.

In the case of powder, which is considered for preliminary catalyst screening tests, it is important to make sure that all the reactor volume is homogeneously filled with the catalyst. To that purpose, Spogis and Nunhez (2009) studied the effect of geometry on solid suspension in stirred tank reactors and were able to make recommendations on operating conditions for proper stirring. It is also possible to consider more complex phenomena such as phase change and solid precipitation (Gavi et al., 2010). CFD developments are quite important in this area since this type of reactor is commonly used in the specialty chemicals sector and has recently gained in importance with the development of biochemistry with issues concerning reactant concentration and shear-stress distributions (Mehmood et al., 2010; Hong et al., 2014).

Once preliminary screening is performed, it is important to check that similar performances are reached with "real" industrial size and shape catalysts. This is discussed in the following section.

\subsection{Catalyst Screening Tool}

Catalysts in the refining industry are usually manufactured in the shape of beads or extrudates with diameters ranging from 1 to $3 \mathrm{~mm}$ for fixed-bed technologies. During the screening step, it is essential to assess the catalyst's intrinsic kinetics in its commercial form, maintaining the spatial distribution of the active sites in the particle, and external and internal mass transfer rates. Only in this way can laboratory measurements be representative of how the catalyst will perform during industrial operation.

Laboratory-scale stirred tank reactors containing a stationary basket have been proposed since the late 1970s for the kinetic testing of commercially shaped catalysts (Mahoney et al., 1978). In these reactors, also known as Robinson-Mahoney reactors, the catalyst is supported and immobilised inside an annular basket manufactured from a metallic net or a perforated metal sheet, and placed inside the reactor (Fig. 3). The gap between the side walls of the annular basket is generally narrow, where the catalyst particles form a shallow packed bed with a length equivalent to 3-10 particles, from wall to wall. An axial flow impeller is placed in the centre of the annular basket, simultaneously promoting the flow through the basket walls and catalyst bed, and quite strong turbulent mixing of the liquid or gasliquid mixture bulk. These catalyst testing devices need to fulfil some essential requirements for allowing a true assessment of the reactions' kinetics (Perego and Peratello, 1999): isothermal operation; appropriate flow distribution and blending times; and the absence of interphase mass transfer limitations.

Robinson-Mahoney reactors are known for having a higher performance compared with laboratory fixed-bed reactors, also frequently used for the testing of shaped catalysts. Due to the strong turbulent mixing promoted by the 

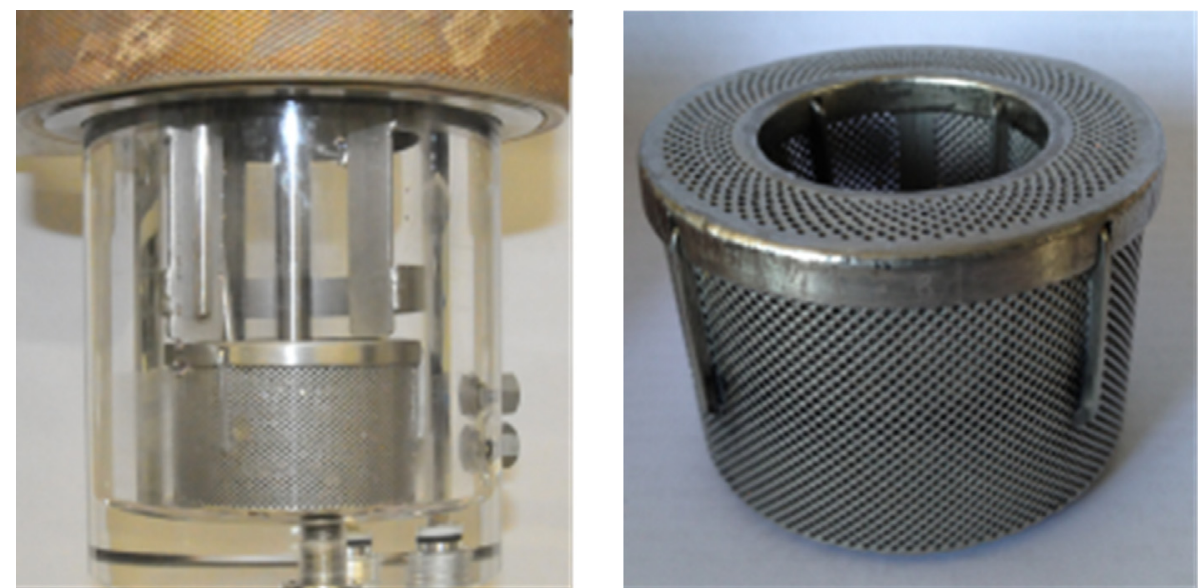

a)

b)

Figure 3

Photographs of a Robinson-Mahoney reactor; a) reactor with a transparent vessel (Braga, 2013), b) stationary catalytic basket.

use of an impeller, mass transfer coefficients between the phases (gas-liquid and solid-liquid) are usually higher (Pitault et al., 2004). Also, due to the strong agitation, these reactors present lower temperature and concentration gradients (Forni, 1997). However, the reactor performance can be affected by operational parameters and the physical properties of the reactants. Geometrical changes to the basket or impeller designs, or the selection of a different catalyst filling, of different shape or size, can also lead to different reactor performances, even when similar operating conditions are chosen. With the continuous development of newer and more efficient catalysts and the growing interest in the use of complex fluids such as heavy crude feedstock or biomass-derived fluids, the catalyst testing and selection task in lab-scale reactors may become hindered by interphase mass transport limitations, external to the particles, or by mixing limitations. In these cases, measuring the mass transfer coefficients prior to the catalyst kinetic assessment is recommended (Pitault et al., 2004).

In spite of the concerns regarding the reliability of the kinetic measurements in more extreme and non-tested conditions, only a reduced number of studies for the characterisation of Robinson-Mahoney-type reactors' hydrodynamics and mass transfer rates has been reported in the scientific literature. The few examples are the works of Pitault et al. (2005), Mitrovic et al. (2005) and Braga (2013), whose reactor set-ups have similar dimensions but different impellers and basket geometries, and catalyst shapes. This small number of reported results occurs mostly because an extensive experimental study of Robinson-Mahoney reactors is neither practical nor economical when a large number of geometrical or operational parameters need to be studied.
As a consequence, the range of applicability of these devices on the kinetic testing of shaped catalysts and the reactor geometry adapted for each application is still not completely known.

Recently, since the pioneering work of Magnico and Fongarland (2006), and later of Santos-Moreau et al. (2012), CFD has been providing an important contribution to the study of Robinson-Mahoney reactors. A CFD model of the reactor can indeed provide a detailed tri-dimensional description of the flow field, with special interest in the flow inside the catalytic basket, which is very difficult to visualise experimentally. The numerical results can then be used to estimate mass transfer coefficients and search for operational regimes of kinetic control, where reaction rates can be truly measured. The complexity of the flow in Robinson-Mahoney reactors poses a difficult challenge when developing a computational model. This is mainly due to the existence of flow zones with quite different turbulent intensities - high turbulence in the region close to the impeller, and low turbulence intensity in the outer region of the basket - and to a strong hydrodynamic interaction between the impeller blades and the basket structure. However, the computational strategy being adopted is the development of low computationallydemanding models, both in computation time and machine requirements, but able to describe the most essential aspects of turbulent mixing and the flow in the catalyst porous medium inside the basket. The Multiple Reference Frame (MRF) approach has been chosen to deal with impeller motion, and RANS modeling to describe the turbulence generated in the reactor, allowing running steady-state simulations. The packed bed of catalyst particles is modeled as a homogeneous porous medium, which allows reducing greatly the number of mesh 

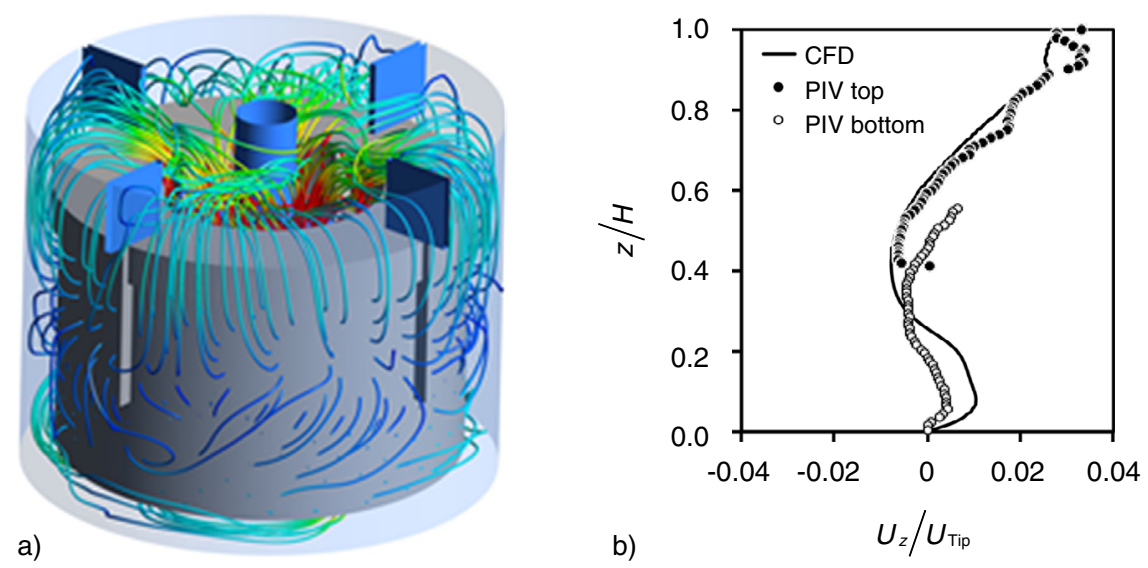

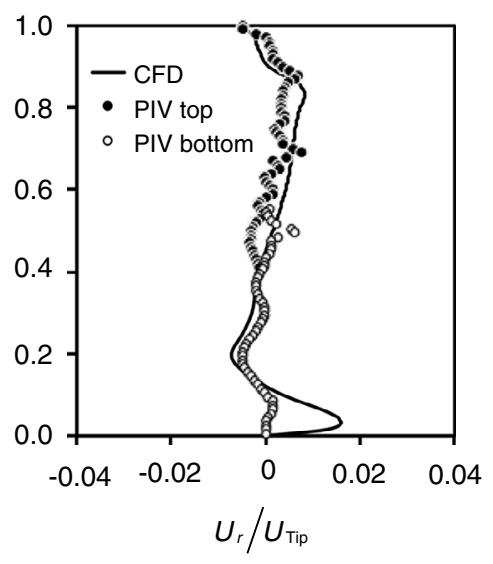

Figure 4

Computational results and model validation; a) time-averaged fluid path lines in the Robinson-Mahoney reactor obtained from CFD, b) comparison between time-averaged velocity profiles obtained from CFD and the PIV results, Braga (2013).

elements necessary to discretise the basket domain. This less computationally-demanding modeling strategy allows obtaining flow results (Fig. 4a) in only a few hours.

In spite of the adopted simplifications, the developed CFD models are able to produce quite satisfactory results. Figure $4 \mathrm{~b}$ shows, for illustration, the good agreement that can be obtained between time-averaged radial and axial velocity components between the outer basket walls of the catalytic basket and the tank walls obtained from CFD simulations and the PIV experiments of Braga (2013). The axial and radial velocity components, $U_{z}$ and $U_{r}$ respectively, are normalised by the speed at the tip of the impeller blades, $U_{\text {Tip. }}$ The axial coordinate, $z$, is normalised by the height of the liquid in the reactor, $H$.

After experimental validation, these CFD models can then be used as a numerical tool for the design of optimised devices. CFD can be used, as an example, to study the effect of the impeller clearance from the bottom of the stirred tank on the flow field and mass transfer rates (Fig. 5). The results from this parametric study allowed finding the optimal positioning of the impeller in the reactor, avoiding the actual need to build testing prototypes and further experimentation.

\subsection{Solvent Screening Tool}

Similarly to catalyst screening, it is of interest to discuss solvent screening, which also requires dedicated tools. In spite of not being shown in Figure 1, amine-based gas treatment processes, often combined with other processes, are required downstream of the HydroDeSulphurisation units (HDS - a specialised HDT) for treating the sour gas containing high hydrogen sulphide $\left(\mathrm{H}_{2} \mathrm{~S}\right)$ content, thus limiting sulphur
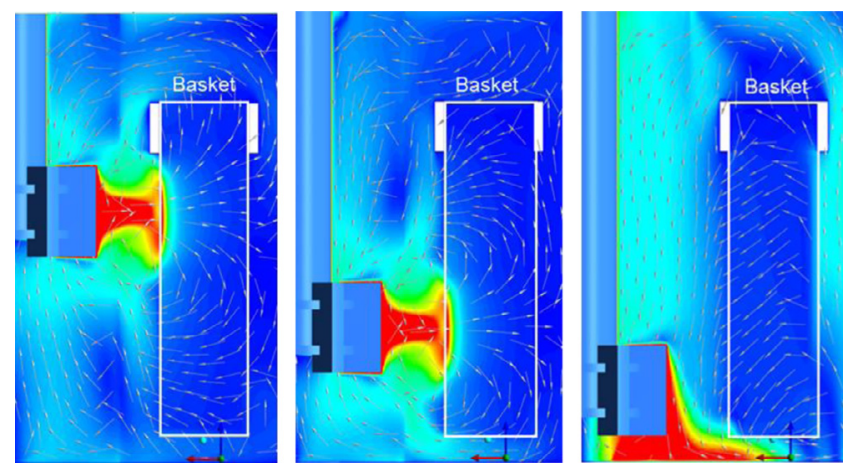

Figure 5

Velocity contour plots and vector maps in the RobinsonMahoney reactor at different impeller clearances from the bottom of the tank.

emissions into the atmosphere. Usually, robust standard amine-based processes are used with MEA or MDEA (MonoEthanolAmine and Methyl-DiEthanolAmine) as solvents. With energy efficiency constraints, refiners may benefit from developments performed in the energy sector on post-combustion capture processes where $\mathrm{CO}_{2}$ contained in the flue gas is absorbed in low-energy-requirement solvents. Such developments need dedicated and precise laboratory tools, in particular thermodynamic cells to obtain Vapour-Liquid equilibrium data and kinetic cells to determine the solvent reactivity. In the case of fast chemical reaction, a wetted-wall column or equivalent string of discs are often considered for kinetic measurements (Chen et al., 2011; Luo X. et al., 2012). In these experimental set-ups, a very thin well-controlled liquid film flows down over a wall of well-known geometry and is surrounded by the acid 


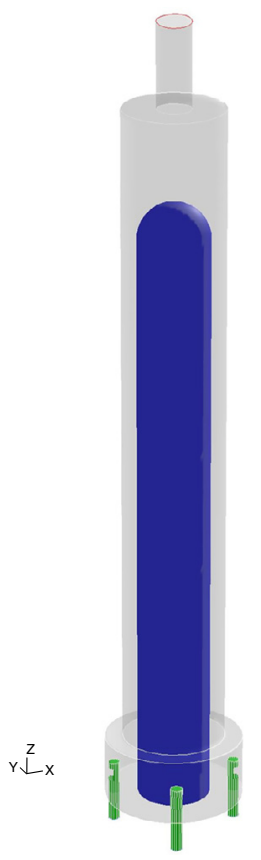

a)

Figure 6

Wetted-wall column flow design; a) general view, b) close view to gas injection - base case, c) optimised injection.

gas in such a way that flow distribution must be perfect with a smooth gas/liquid interface. A few years ago, IFP Energies nouvelles (IFPEN) designed its own wetted-wall column with the help of CFD concerning special items. As illustrated in Figure 6, the aim of CFD simulations was to check the quality of the gas phase distribution around the central cylinder over which the liquid flows. From simulations, considering various gas injections, it was possible to set a minimum number and type of injection points. For the same number of injection points, two types of injectors were tested. In Figure 6b, one can observe significant non-homogeneities in the velocity contours; in Figure 6c, one can observe a much better flow distribution, although not yet perfect, indicating that four injection points were not enough. Finally, a special multiple injection system, as described by Servia et al. (2014), was retained.

Finally, once the catalyst, the separation agent or solvent, has been selected, the most important phase (that is the development step both on the catalytic side and on the reactor design side) has to be addressed. CFD is rarely used today for the catalyst development and for its different production steps (mixing, spraying, impregnation, drying, etc.); the following examples thus focus on the chemical reactor design, showing different types of inputs that can be obtained on different scales.

\section{DEVELOPMENT}

\subsection{Trickle-Bed Reactors}

\subsubsection{Trickle-Bed Reactors on a Local Scale}

As mentioned in Section 1, trickle-bed reactors are frequently used for hydrodesulphurisation, hydrocracking (HCK) and in general for HDT processes of various oil cuts. For decades, catalysts involved in HDT or HCK reactors have been continuously enhanced both in terms of intrinsic reactivity and physical access to active sites throughout the particle volume. At the same time, new catalyst shapes are proposed by licensors, such as trilobes, quadrilobes, asymmetric shapes and so on. Although arguments relative to the catalyst effectiveness are proposed, it is not trivial for the final user to understand the exact effect of the catalyst shape and size on its own process.

Actually, the purpose is complex. It involves several physical phenomena on various scales. On a macroscopic (reactor) scale, catalyst geometry impacts active solid loading, pressure drop and global holdup of different fluid phases. On a meso-scale from tens to thousands of particles, the degree of homogeneity of the product concentrations and temperature may be affected, leading to undesirable hot spots and heterogeneity of particle reactivity. On the particle scale, the shape can modify external interphase transfers and wetting of particles (in the case of trickling flows). Inside the catalyst particles, the diffusion lengths to be travelled by molecules also depend on the particle geometry. Finally, mechanical strength has to be considered, as catalyst particles are generally gravity-loaded several times during their lifetime. Considering the problem from a one-sided point of view may lead to erroneous conclusions (Cooper et al., 1986).

In this context, CFD can be a powerful tool to deal with (multi-)fluid-solid interactions and their consequences on local and global transport properties. Realistic particle loadings can be simulated by mechanical models (Zou, 1995; Augier et al., 2010a) or characterised by non-intrusive analysis such as MRI or X-Tomography, leading to the extraction of usable meshing domains for simulation (Sederman and Gladden, 2001; Larachi et al., 2014). Otherwise, in the case of multi-fluid flows, interface reconstructive models are of special interest. In particular, VOF models are popular as they are easy to use even in complex geometries. They can give information on the wetting efficiency of the catalyst and its dynamics (Heidari and Hashemabadi, 2013). 


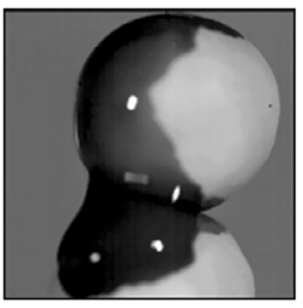

a)
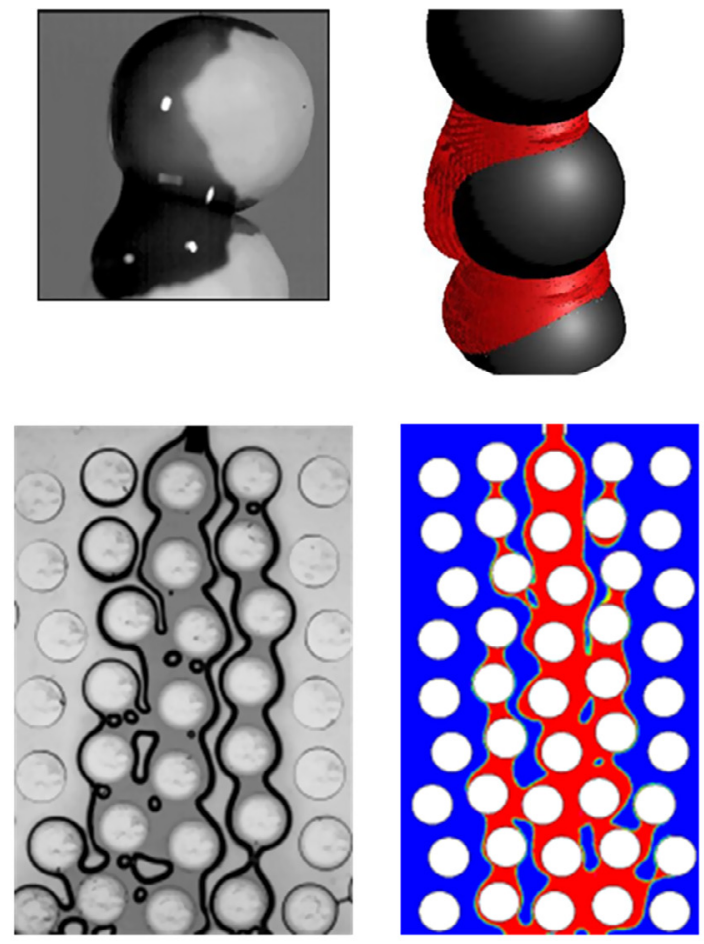

b)
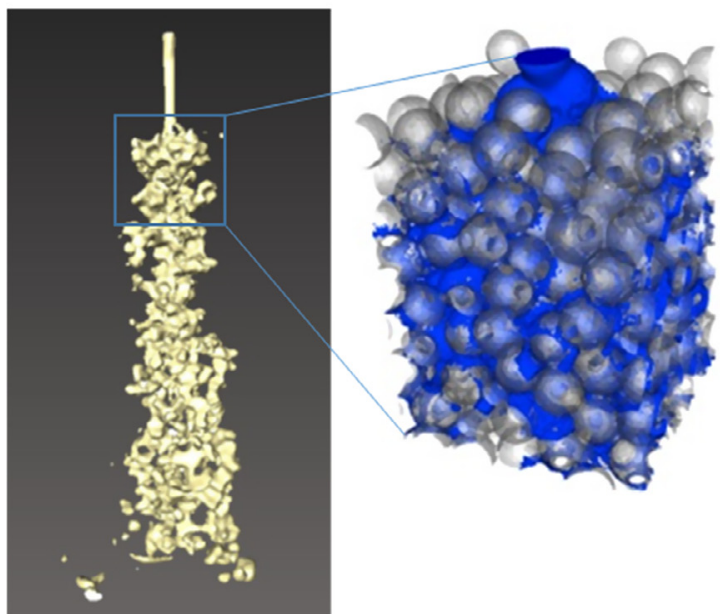

c)

Figure 7

Comparison between experiments (left) and CFD-VOF simulations (right) on different scales: a) on the particle scale (Augier et al., 2010b); b) on the meso-scale for 2D flow (Horgue et al., 2013); c) on the scale of hundreds of particles.

This kind of calculation was initially limited to small calculation domains, of several particles, because of their high $\mathrm{CPU}$ usage and being time-consuming. Figure 7 reports different CFD calculations of trickling flows between spherical particles, operated on different scales. A qualitative comparison with experiments is proposed:

- 3-particle-scale 3D simulation (Augier et al., 2010a);

- 36-particle-scale pseudo-2D simulation (Horgue et al., 2013);

- over 300-particle-scale simulation performed in 2014 on a 64-processor cluster.

More quantitative comparisons have also been reported in the cited papers. Similar calculations are possible with more complex shapes of particles. Given the possibility to perform direct simulation on hundreds of particles, statistics and averaging procedures (Whitaker, 1999) can be applied to representative elementary volumes in order to develop rigorous closure laws for macroscopic porous models. Friction forces for pressure drop analysis and apparent viscosity are, for instance, terms that need to be specified in macroscopic models.

Another use of local CFD simulations consists of additionally solving the transport of passive scalars (such as chemical species or temperature) in established flows. Different scalar boundary conditions can be applied at the domain inlet or at particle surfaces in order to calculate axial/transversal dispersion properties or liquid/solid transfer coefficients, respectively (Augier et al., 2010a). As an example, the $L / S$ mass transfer coefficient $\left(k_{l s} \times S\right)$ around single particles was calculated in two dimensions for different Reynolds numbers and shapes of particles. Figure $8 \mathrm{a}$ shows the results corresponding to 3 different shapes of extruded catalyst particles: cylinder, perfect trilobe and smoothed trilobe. In the same figure, the associated concentration profiles of liquid reactants are also reported to illustrate the differences between particle shapes. One can see the significant differences in the overall transfer coefficient $\left(k_{l s} \times S\right)$ between shapes because of dead volumes between lobes and the heterogeneity of diffusive film thickness at the particle surface. On a lower scale, CFD solvers can also be used to calculate transport of chemical species by diffusion inside catalyst particles, and their consumption or production by reaction. Associated partial differential equations are solved in complex geometry including particle shape, heterogeneous wetting of catalysts, if any, and phase change inside particles in the case of vaporisation (Kirillov et al., 2002; Bazer-Bachi et al., 2011). In the case of a single reactant, the problem can generally be tackled by one-dimensional approximations, and classical approaches based on the Thiele modulus, Biot or Prater numbers are usable through some adaptation of characteristic lengths. However, in more complex cases, involving several reactants in gas and liquid phases, for example, CFD-based multidimensional approaches have to be used to calculate the effect of transport phenomena on the catalyst effectiveness factor (van Houwelingen et al., 2010; Schwidder and Schnitzlein, 2012). 

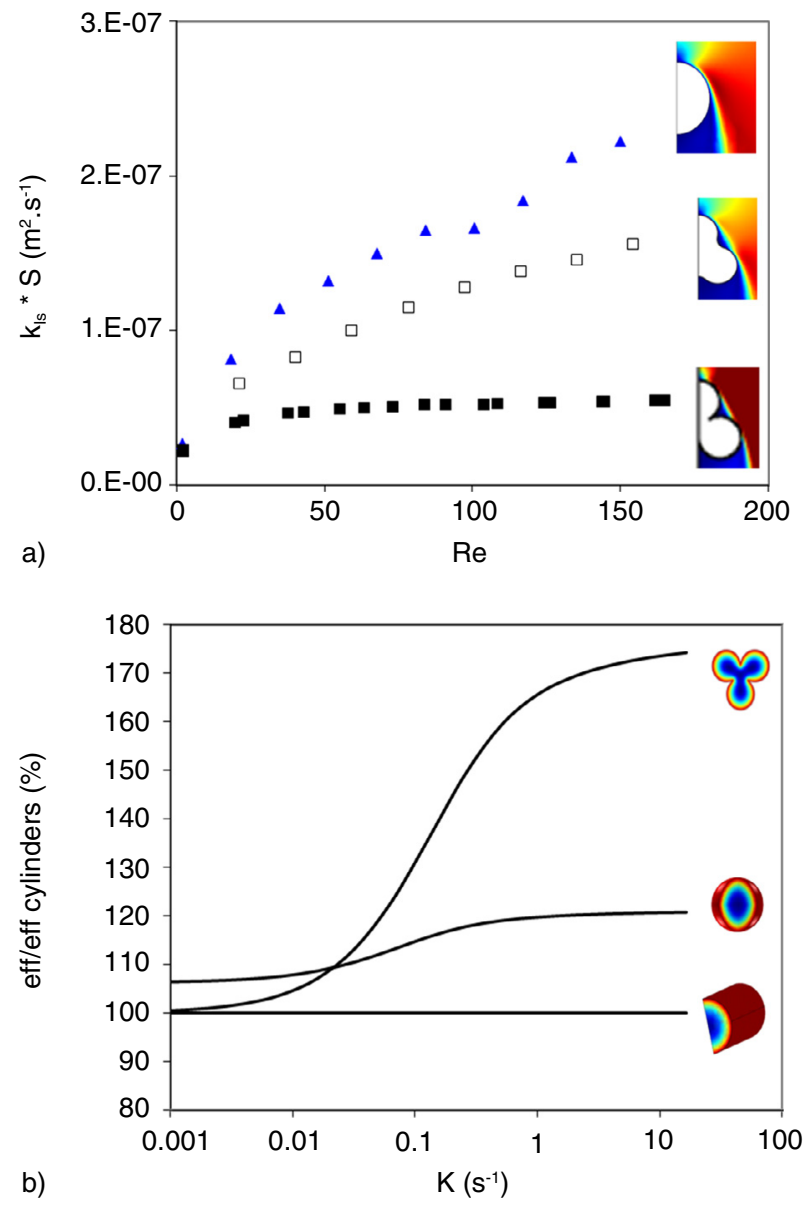

Figure 8

Effect of catalyst shape on: a) liquid-solid mass transfer $\left(k_{l s} \times S\right)$, and b) global reactor efficiency depending on the kinetic constant $K$. Results are normalised by the efficiency corresponding to the cylindrical shape.

From the final user's viewpoint, a good catalyst is a more efficient one without increasing pressure drop inside existing reactors. A comparison is proposed between 3 simple catalyst shapes: sphere, cylinder and trilobe, to illustrate the topic. External transfer limitations are neglected and in this simple example, pressure drops are calculated using the model of Tosun, including particle size and shape effects (Tosun, 1984). The 3 considered particle shapes lead to different loading density, pressure drops and diffusion limitations. In Figure 8b, a comparison between overall catalyst efficiencies is presented, calculated by cubic metres of the catalyst bed, at iso-pressure drop, and as a function of the considered 1 st-order reaction kinetics $K$. The higher the reaction rate $K$, the stronger the diffusion limitation. Calculations are normalised by the efficiency obtained for cylinders. The results show that the best shape depends on the diffusion regime. At low values of $K$, the Thiele modulus is small (chemical regime); the best shape is the one leading to the more dense catalyst loading, which is the sphere (the solid fraction is up to $66 \%$ ). Inversely in the diffusion regime, the best shape is the most irregular as it provides more surface at the iso-catalyst volume and thus decreases diffusion lengths inside solids. The lower loading density associated with trilobes decreases the pressure drop and allows one to use smaller particles to reach a targeted pressure drop. This also contributes to the efficiency of catalysts in the diffusion regime. This simple illustration shows how multi-scaled phenomena interact. With the development of massively parallel computing, more realistic fluid dynamics representation may be used in the future, including wetting phenomena, concentration and flow heterogeneities between particles, and thus for different reaction kinetics.

\subsubsection{Trickle-Bed Reactors on the Bed Scale}

Catalytic Trickle-Bed Reactors (TBR) consist of a fixed bed of solid catalyst particles contacted by a co-current gasliquid downflow. The reaction occurs between the dissolved gas and the liquid phase at the catalyst surface or inside the catalyst pellet. In the last decade, the increasing environmental standards of fuels have led to the development of high-performance units with improved catalyst activities. However, an efficient catalyst relies on a perfect liquid distribution over the catalyst bed's cross-section. Thus, the hydrodynamic distribution is of prime importance in HDT/HDS operations, especially due to the increased demand on catalyst performance. Indeed, the uniform distribution of gas and liquid above the catalyst is very important to achieve the optimum performance of the catalyst.

Hydrodynamic distribution study inside the catalytic bed is often carried out in a laboratory column of moderate size (diameter lower than $1 \mathrm{~m}$, since it is quite difficult to perform experimental tests on very large-diameter columns) with ideal horizontal trays and model system fluids (water/air). However, in the industrial reactors of several meters in diameter, trays are often not perfectly levelled (Maiti and Nigam, 2007; Alvarez et al., 2007; Bazer-Bachi et al., 2013) because of their weight or because of column deviation from verticality. In this case, the horizontality default of the distributor tray becomes an important factor that must be carefully considered. Indeed, when the distribution of liquid reactants is not perfect on catalyst beds, preferential liquid flows appear, causing radial temperature gradients and loss of conversion. This phenomenon leads to increasing the temperature at the inlet of reactors, with associated negative consequences concerning cocking and deactivation of catalysts.

In this context, CFD simulation has become a very interesting tool to study the effect of maldistribution on reactor efficiency and to ensure the scale-up to industrial reactor size. 
As discussed above, in recent years, many interesting CFD approaches have been considered to solve the two-phase flow hydrodynamics in trickle-bed reactors. For the bed-scale simulation, the Eulerian two-fluid approach appears to be very interesting since the real physical geometry of the bed is represented by an effective porous medium, which leads to significantly reduced calculation time when compared with interface capturing methods (such as VOF or Level Set methods). The Eulerian two-fluid approach is based on an averaging method of local gas and liquid mass and momentum conservation equations, the packed bed being represented as an "effective porous medium" (Wang et al., 2013; Solomenko et al. 2015). Since these models do not directly simulate the flow over the real physical geometry, one should deal with a closure problem where interactions with the solid surface of particles, as well as fluid-fluid interactions, should be accounted for through specific closure laws. Recently, Solomenko et al. (2015) proposed adapted closure laws for fluidsolid interactions, gas-liquid interaction, and dispersion mechanisms that contribute to the liquid dispersion inside the catalyst bed, based on capillary and mechanical forces as respectively proposed by Attou and Ferschneider (2000) and Lappalainen et al. (2009). The authors show that these dispersion mechanisms should be taken into account in the simulations to reproduce gas-liquid hydrodynamic flow in TBR well. They validated the CFD model upon various experimental data of liquid distribution obtained by Marcandelli et al. (2000) and Boyer et al. (2005). Figures 9 and 10 show simulation results obtained by Solomenko et al. (2015) in order to evaluate CFD modeling. The simulation results were compared with the experimental data of Marcandelli et al. (2000). The experimental work consists of liquid distribution in a $0.3 \mathrm{~m}$-diameter and $1.3 \mathrm{~m}$-high column packed with 2-mm glass beads using air and water. The gas phase was fed through four 25 -mm-internal-diameter chimneys, while liquid was injected through two 2.5-mm-internal-diameter orifices in the co-current mode. The liquid flow rate distribution in the bed was measured using 9 collectors of equal surface at the bottom of the column. Simulations were carried out considering a 3D grid that represents half of the column. The simulation domain was chosen so that the symmetry of the flow about plane $x y$ is fulfilled. Gas and liquid, flowing in the co-current mode, were introduced into the domain through velocity inlet conditions and the gauge pressure was specified at the trickle-bed outlet. The superficial velocities of gas and liquid used for simulation are, respectively, $3.10^{-3} \mathrm{~m} . \mathrm{s}^{-1}$ and $5.10^{-3} \mathrm{~m} . \mathrm{s}^{-1}$ (Marcandelli et al., 2000). As discussed in Solomenko et al. (2015), relatively small time steps, varying between $1.10^{-5} \mathrm{~s}$ and $1.10^{-2} \mathrm{~s}$, were required for this simulation.

Figure 9 shows liquid saturation contours in the simulated trickle-bed for the configuration of two liquid injection

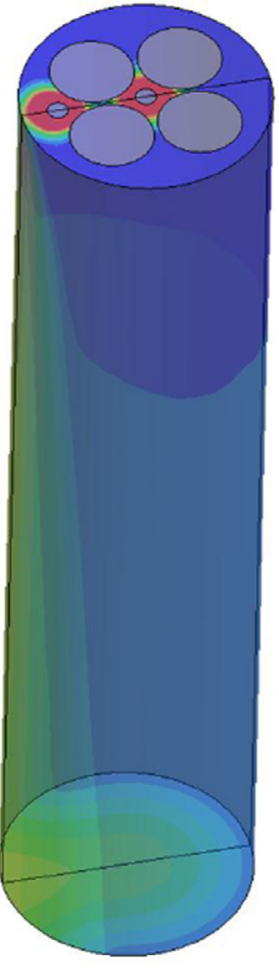

a)

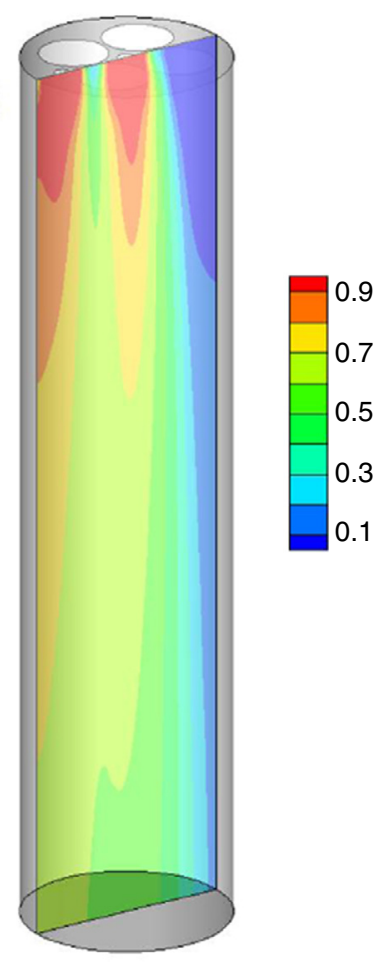

b)

Figure 9

Contours of liquid saturation obtained by simulation in the case of Marcandelli et al. (2000) experiment. a) On the entire domain, b) on the symmetry plane, Solomenko et al. (2015).

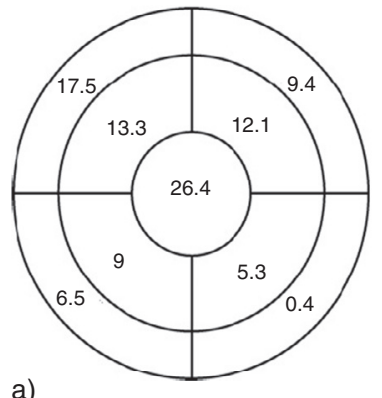

a)

Figure 10

Liquid distribution at the bottom of the trickle-bed in terms of $\%$ of total liquid flow rate. a) Experimental results (Marcandelli et al., 2000), b) simulation results, Solomenko et al. (2015).

points considered in Marcandelli et al. (2000) experiments. The plot shows the liquid spreading along the column. The dissymmetry of liquid patterns in the top of the column is gradually attenuated at lower positions inside the trickle-bed. 
Figure 10 shows, respectively, the experimental and the CFD liquid distribution at the bed outlet; the ratio of the liquid flow rate in each collector to the total liquid flow rate is given. One can observe very good agreement between the experimental and numerical data, bearing in mind that relative errors on measured liquid flow rates are evaluated between $8 \%$ and $10 \%$. Moreover, the simulation predicts a global maldistribution factor (as defined in Eq. 1) of $27 \%$, which is quite close to that reported by Marcandelli et al. (2000), whose value is $23 \%$ :

$$
M_{f}=\sqrt{\frac{1}{N(N-1)} \sum_{i}\left(\frac{Q_{i}-Q_{\text {mean }}}{Q_{\text {mean }}}\right)^{2}}
$$

These studies show that the bed-scale liquid distribution in TBR can indeed be well predicted by CFD. Such CFD modeling can thus be very useful to understand the impact of maldistribution on reactor efficiency well, and to ensure the scale-up of TBRs to industrial size. For further studies, such as hydrodynamic, simulations can be coupled with chemical species transport and chemical reaction to relate the quality of distribution to the catalytic performance and thus define the design criteria for distribution technologies better.

\subsection{Bubbly Flows}

As discussed in Section 1, bubbly flow is mostly encountered in distillation columns equipped with distillation trays. Sieve trays or valve trays are preferred to old bubble-cap trays, but in all cases the flow configuration, at least just above the tray, is mainly of churn turbulent bubbly flow type. This type of flow is also encountered in many other chemical processes and deserves significant attention within the framework of the FT process. In both cases illustrated hereafter, the Euler/Euler approach is considered for modeling, the bubbles being the dispersed phase in the liquid phase.

\subsubsection{Case of Distillation Column Trays}

CFD can help to understand the flow configuration and characteristics better, especially in terms of liquid holdup and flow dispersion. Among the numerous articles dealing with that subject, the paper by Krishna et al. (1999a) can be considered as a pioneering work. The authors showed that, provided an appropriate drag law is selected for the interphase momentum exchange term, the Euler/Euler model is appropriate to determine the clear liquid height above the tray. The calculations were performed on a simplified rectangular tray and the results were compared with experimental data obtained on a set-up with similar geometry. The clear liquid height determined by CFD was found to be overestimated in comparison with experimental data. However, its trends as a function of the liquid flow rate, the gas flow rate and the weir

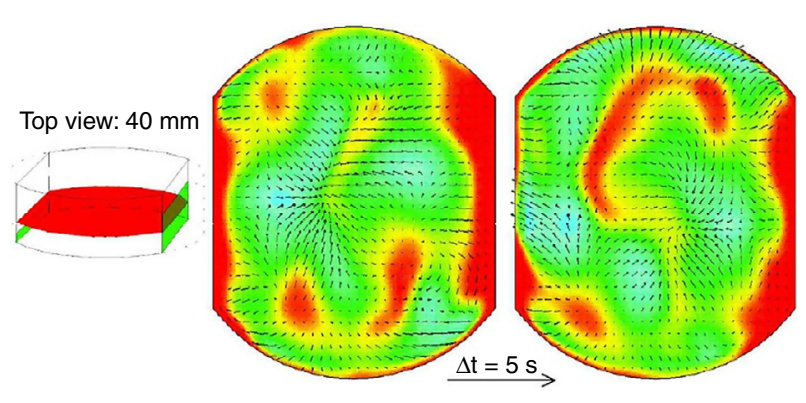

Figure 11

Snapshots of the liquid volume fraction contour, Krishna and van Baten (2003).

height are in good agreement with what was experimentally observed. It was thus concluded that the use of the CFD tool should be amplified. Among several other papers from the same group, from the University of Amsterdam, the article by Krishna and van Baten (2003) is of particular interest since first, the geometry can be considered as more realistic, the column shape being circular, and more importantly, because a comparison is made between configurations with and without catalyst containers placed on the tray with application to reactive distillation. Figure 11 shows two snapshots of the flow with a view from above, the liquid flowing from left to right; the colour map corresponds to liquid holdup values and the arrows to liquid velocity vectors. Such a simulation shows the quite chaotic character of the flow, with local flow recirculation patterns and local flow directions somewhat different from the mean flow. This behaviour shows that a simple 1D analysis of the flow would not be sufficient to describe the liquid phase flow. The study illustrates the important differences observed in terms of flow structure and liquid holdup between the cases with and without gas injection. Moreover, it shows that liquid residence time calculation is possible, which is of high importance when a catalytic reaction takes place. More recently, it has been shown that CFD could also be used for the design and optimisation of tray orifices. Indeed, Li et al. (2014) performed calculations to study the effects of an original fixed-valve tray geometry by combining the use of Euler/Euler and VOF approaches. Comparison with experimental measurements for clear liquid height determination is made, and a detailed description of the flow at the valve is presented, which would be very difficult to perform experimentally.

\subsubsection{Case of Bubble Columns for Fischer-Tropsch Process Development}

More than 20 years have been required to be able to match CFD simulations with the reference measurement made by 


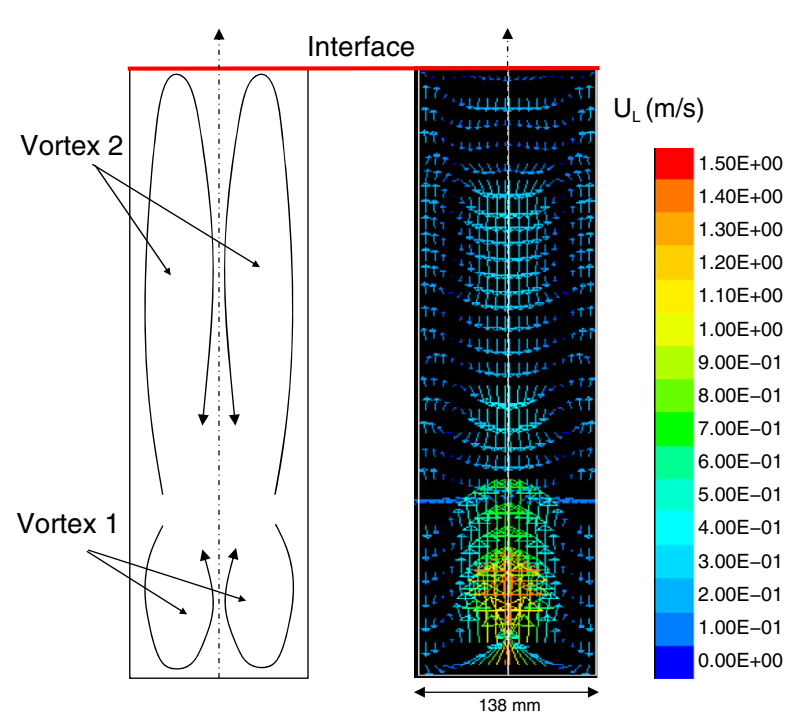

Figure 12

Sketch of the two-phase flow inside a bubble column before steady state is reached with corresponding liquid velocity vectors.

Hills in 1974 (Hills, 1974). Among the first studies, Lappin and Lübbert (1994) and Boisson and Malin (1996) showed that it was possible to be able to obtain the main flow behaviour, that is a large liquid recirculation pattern in the shape of an elongated torus with a maximum liquid velocity along the central axis. This liquid recirculation is induced by ascending bubbles, since bubble drag corresponds to a transfer of momentum from the gas to the liquid. Satisfactory agreement was obtained between simulations and experiments for the radial void fraction and radial liquid velocity profiles. However, some difficulties have to be faced. First of all, simulations are quite unstable and to obtain the expected recirculation pattern, one has to proceed to long unsteady calculations before a steady state is reached. During the non-stationary process, several recirculation cells, or largescale vortices, can form, making the calculation procedure long and complex if no simplifications are assumed; such as, for example, gas injection on a central portion only, as discussed by Raynal et al. (2001). As an illustration, Figure 12 shows both a simplified flow pattern with two vortices and the corresponding liquid velocity vectors. Second, one needs adapted closure laws, both on gas/liquid interaction terms and on the bubble diameter. Boisson and Malin (1996) showed that, in this special gas-induced flow, the drag law is prominent when compared with other interactions (lift, added mass or Basset effects), and Raynal (2005) discussed the sensitivity toward the bubble diameter for a given set of drag laws and showed that the latter could

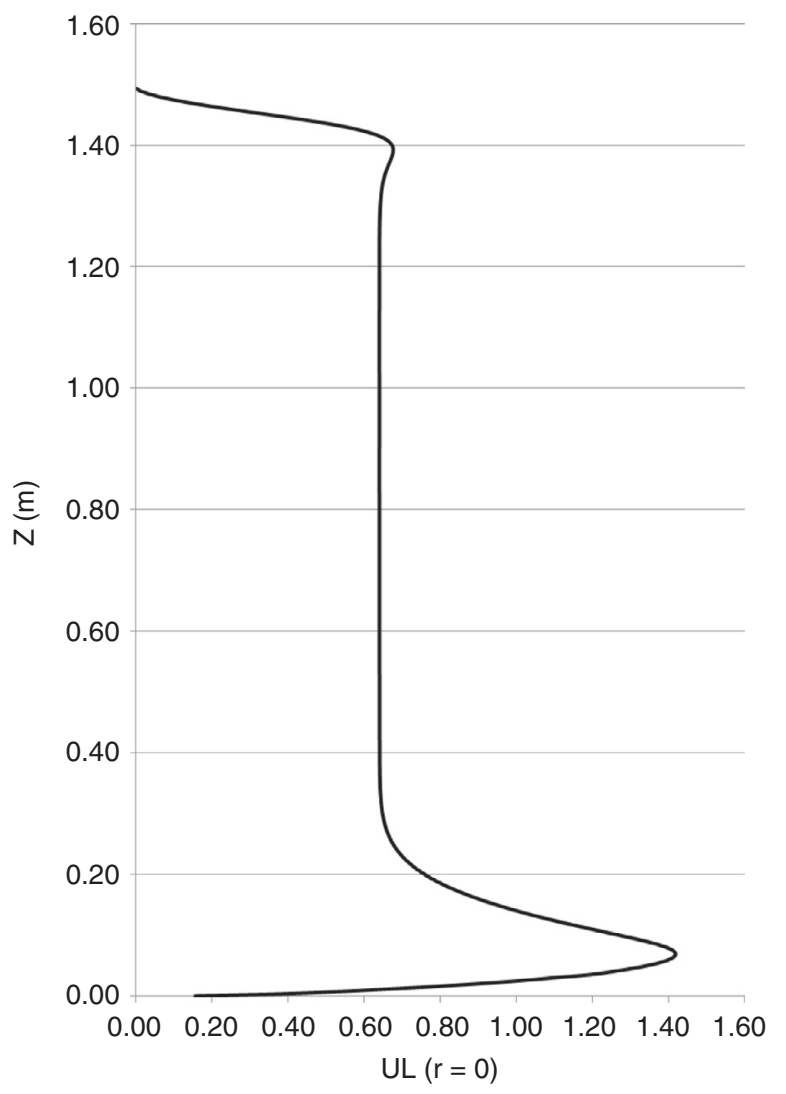

Figure 13

Liquid velocity profile along the axis $-D=138 \mathrm{~mm}$, $V_{S G}=16.9 \mathrm{~cm} / \mathrm{s}$.

not be neglected but was not too important. Indeed, an increase of $25 \%$ in the bubble size results in a decrease of the centreline liquid velocity along the axis of only $8 \%$. Once steady state is reached, the axial velocity profile, as can be seen in Figure 13, shows a region of fully established flow with a plateau value for the liquid velocity. This is this latter centreline velocity, $V_{C L}$, which is compared with experiments. Despite the good agreement between simulations and experiments observed on small-diameter columns, here of $138 \mathrm{~mm}$ as used by Hills (1974), data for large diameters was lacking; the process development indeed aims at designing columns of diameters closer to $10 \mathrm{~m}$. Several studies have been dedicated to this extrapolation issue, with an important input from the group of Professor Krishna. Krishna et al. (1999b, 2000) discussed the large number of existing correlations for the centreline liquid velocity with a huge discrepancy observed when applied to large diameters above $5 \mathrm{~m}$, ranging from 1 to almost $5 \mathrm{~m} . \mathrm{s}^{-1}$. The potential of CFD was to discriminate between the existing correlations or possibly propose a new one. Simulations 
were performed for diameters up to $0.63 \mathrm{~m}$, which made possible a first choice among all correlations identified in the literature. Two correlations were considered since they were found to be in better agreement with CFD and with some experimental measurements. However, since some discrepancies were still observed, it was mentioned that further experimental work was needed on larger-diameter columns to confirm the strong scale dependence observed with the Euler/Euler simulations. This work was completed by van Baten and Krishna (2004) with simulations up to $10 \mathrm{~m}$; 3D simulations were shown to be more representative of the flow, in particular in terms of void fraction radial distribution, little discrepancy being observed regarding liquid velocity. This is in good agreement with what was later obtained by Chen et al. (2011). From experimental measurements performed for diameters up to $1 \mathrm{~m}$ and CFD simulations performed for diameters up to $10 \mathrm{~m}$, the correlation proposed by Zehner (1986) was chosen to be the most adapted. Similar simulations were performed at IFPEN with a 2D approach for diameters ranging from 0.15 up to $5 \mathrm{~m}$ and for high gas velocities ranging from 2 to $20 \mathrm{~cm} . \mathrm{s}^{-1}$ (Raynal, 2001). The objective was quite similar to the one described above; that is, performing CFD simulations to identify the most adequate correlation that would be used for design purposes (heat exchange transfer coefficient determination, catalyst attrition conditions, vibration calculations, etc.). The results were compared with correlations suggested by Krishna et al. (2000) and also with some other results obtained in the group of Prof. Miyauchi, who had the opportunity to perform measurements of gas holdup, liquid velocity and mass transfer in an industrial column of $5.5 \mathrm{~m}$ in diameter and $14 \mathrm{~m}$ in height (Koide et al., 1979; Kojima et al., 1980; Kataoka et al., 1979). Among those correlations, one was preferred to give the reference value for the liquid centreline

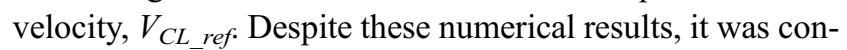
sidered that the risk of extrapolating to diameters up to $10 \mathrm{~m}$ was too high for making safe designs and, as a consequence, original measurements were performed at IFPEN on largediameter columns. The experimental data obtained by Forret et al. (2003) on a 1-m-diameter column and by Schweitzer (2003) on a 3-m-diameter column are shown in Figure 14 with a comparison with the a priori CFD-chosen reference correlation. Normalised liquid centreline velocity values are plotted versus the gas superficial velocity. One can observe that the agreement is not fully satisfactory; ideally all points should be on the $y=1$ line, and more reasonably equally distributed between the dashed lines, corresponding to a $\pm 20 \%$ discrepancy. It is, however, observed that, in most cases, the reference correlation underpredicts the measured values. Nonetheless, most experimental points deviate from the reference correlation by less than $+30 \%$, the average deviation being $+19 \%$ for the $D=3 \mathrm{~m}$ case, the "newly obtained" experimental values being especially well represented by the

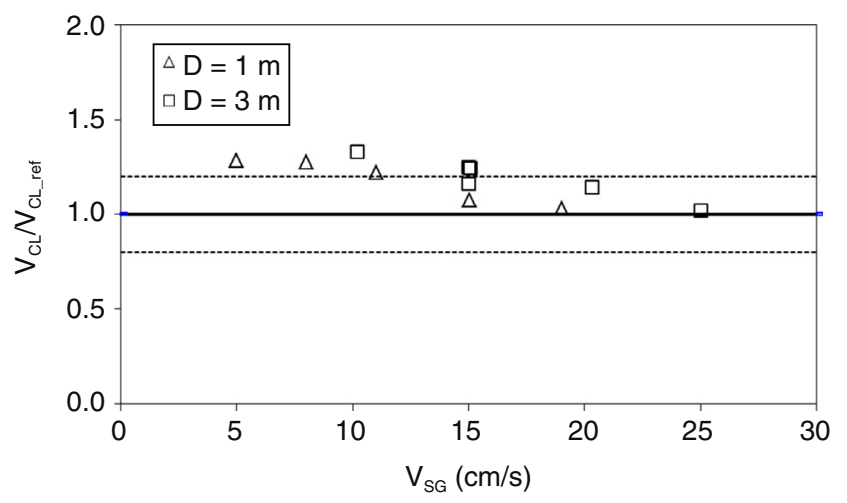

Figure 14

Comparison between predicted and experimental values for the liquid velocity profile along the axis for large-diameter columns, normalised liquid centreline velocity versus superficial gas velocity. The dashed lines correspond to 0.8 and 1.2.

CFD-based reference at high gas superficial velocities, which confirms the potential of such an approach for extrapolation purposes.

The scale-up in diameter is a first important step to go beyond; however, other parameters are also of importance, namely physical properties of fluids, such as gas density, liquid viscosity and surface tension, which have been partially addressed by Krishna and van Baten (2001, 2002). In fact, those influences are mainly imposed via bubble size, which can be considered as mono-dispersed (work performed at IFPEN) bi-dispersed (work performed at the University of Amsterdam) or poly-dispersed (Chen et al., 2005). However, to develop and implement coalescence and breakup complex models, such as those described by Olmos et al. (2001) and Sanyal et al. (2005), further information is required. Indeed, such models use closure laws, or kernels, based on theoretical approaches, as given by Luo H. and Svendsen (1996), for example, or on experiments, which are rather scarce for high void fraction bubbly turbulent flows.

Another difficulty to surmount is the influence of the heat exchanger that will have to be inside the vessel to control the reactor temperature. Larachi et al. (2006) performed a first study on that difficult aspect. They showed that the presence of bundles of vertical heat-exchanger tubes could significantly affect the well-known liquid circulation pattern. Different internal geometries were tested and, in some cases, the ascending central structure was found not to exist any longer; on the contrary, a central downward flow was observed. Since quite different and not fully explained results were obtained depending on the choice of heatexchanger tube configurations, one can consider that this subject is still open for further studies. 
From this very complex example, it can be seen that work is still needed, first on a local scale to develop a better comprehension and modeling of bubble interaction and properties. Second, Euler/Euler approaches also need to be further developed to be able to consider internals within gas-liquid bubbly flow. It is believed that there will be many other applications which will drive such developments, in particular due to the recent development of biomass use for large-scale industrial processes for which gas-liquid flow modeling will face similar challenges to those that FT development is facing (Jiang et al., 2014).

\subsection{FCC Gas-Solid Flow}

As described in Section 1, FCC is a very important process for the refinery with a high complexity, and some similarities with gas bubbles in liquid discussed in the preceding section. In both cases, a dispersed phase strongly interacts with a continuous phase in such a way that the Euler/Euler approach with a two-way coupling is well adapted. In the FCC riser a huge number of solid particles are interacting with a hydrocarbon mixture which, due to low or moderate pressure and high temperature conditions, vaporises and cracks to form lighter compounds and behaves almost like a gaseous phase. Professor Gidaspow proposed an original approach for modeling the solid as a fluid via a kinetic approach and a granular temperature concept (Gidaspow, 1994), which has been seen to be successful for global flow patterns in risers (Neri and Gidaspow, 2000; Jiradilok et al., 2006). This approach is different from what can be obtained with a multi-scale approach as used by van der Hoef et al. (2004), but it can be seen as an efficient approach to perform more applied process design calculations. Indeed, it makes it possible to consider not only mass transfer (Chalermsinsuwan et al., 2009a, b) but also cracking chemical reactions (Lopes et al., 2011). Lopes et al. (2011) used a relatively simple lumped kinetic scheme considering only four main compounds (gas oil, gasoline, coke and light gases) and were able to obtain close agreement with data obtained by Derouin et al. (1997), as can be seen in Figure 15a. The reaction kinetics modeling can of course not be as precise as that which can be done in more standard 1D chemical engineering reactor modeling (Gupta et al., 2007), which considers a larger number of pseudo-components with a more detailed kinetic mechanism scheme. However, and as can be seen in Figure 15b, CFD offers the opportunity to study some 3D effects which can be important, for example, for predicting local hot spots whose occurrences depend on some injection configurations that can be optimised.

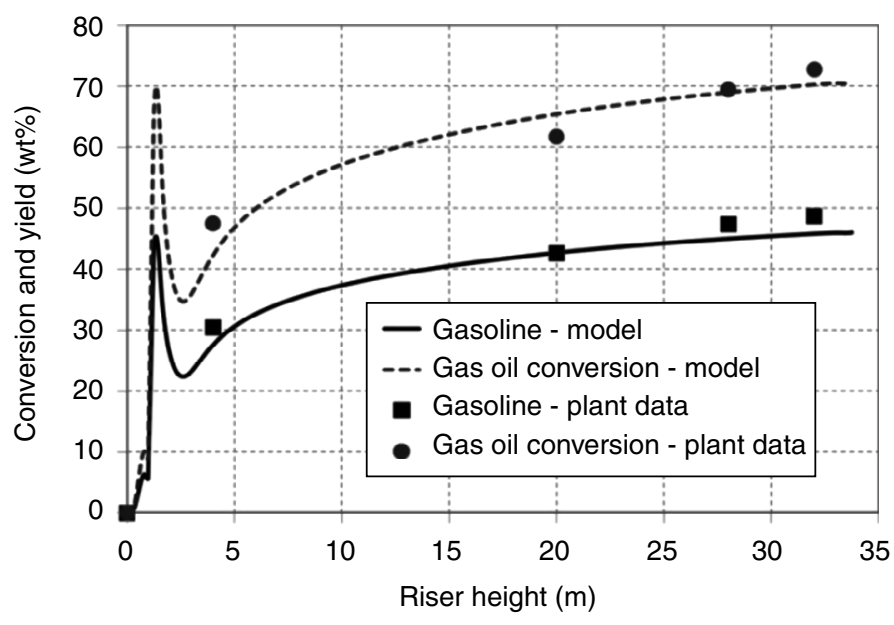

a)

Figure 15

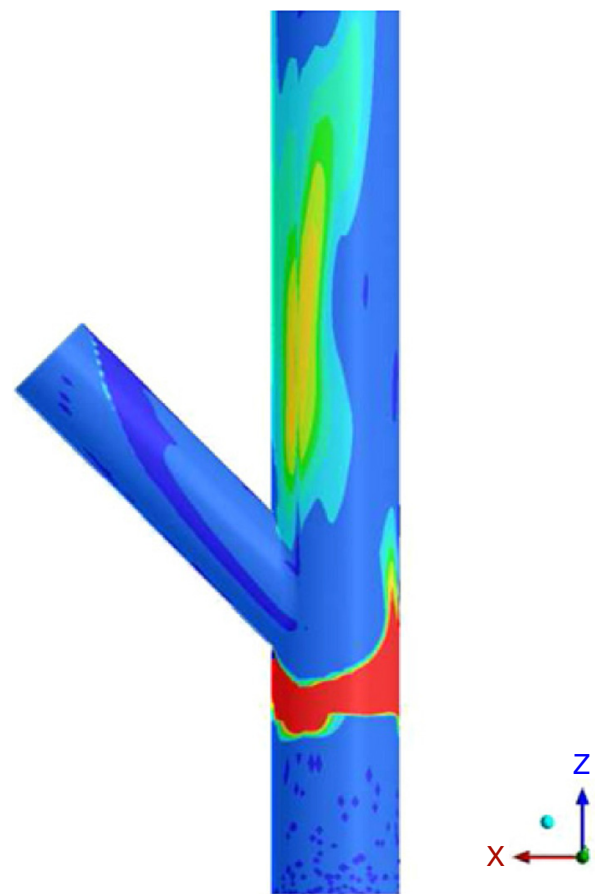

FCC riser simulations by Lopes et al. (2011). a) Axial conversion profile, comparison between CFD and experimental results, and b) temperature contours at the bottom of the riser. 
Note that, even if CFD simulations are mostly focused on risers, some deal with regenerators with a focus on coke combustion modeling (Moula et al., 2013). Such developments are important since the regenerator is of high capital cost and its optimisation could be addressed by CFD simulations in terms of catalyst and air injection systems and associated mixing.

\section{DIAGNOSTICS, TROUBLE-SHOOTING AND EQUIPMENT DESIGN}

In many cases, process development assumes perfect flow distribution and reaction section designs are made accordingly. However, it is well known from feedback from the field that industrial plant operation needs technical support to understand phenomena which were not expected; hot spots observed with thermocouples in fixed bed reactors, local high pressure drop, bad separation performances, etc. Another important role of CFD is to solve these operational issues by providing new technologies that make possible an operation as close as possible to that expected. This role is increasingly considered during the development step. However, in some cases, the demand arises only once the problem is observed in the industrial plant and must be solved as quickly as possible. Hopefully, the required time for CFD studies' start-up is very short. In this section, three examples are given; they illustrate how CFD can be used for reactor internal development for optimal flow and temperature distribution.

\subsection{Gas Solid Flow in a Catalytic Reformer}

Although CCR could appear to be a mature refining process, constant improvements are still required in order to optimise catalysts and reactor/regenerator internals. The role of CFD is illustrated by an example consisting of the optimisation of the oxychlorination internals in CCR regenerators.

The Continuous Catalytic naphtha Reforming process implements a reaction zone with typically four reactors and a catalyst regeneration zone with several stages: a combustion stage, an oxychlorination stage followed by a calcination stage, and finally, a reduction stage (Antos and Aitani, 2004).

In the regenerator, the catalyst circulates in a downward direction. In the bottom of this regenerator, a calcination gas is injected under the calcination annular zone, generally at the periphery using external baffles. Then, it goes through the calcination moving bed in countercurrent compared with the catalyst. This gas is then mixed with an oxychlorination gas, directly in the moving bed at the bottom of the oxychlorination section: the mixture crosses the oxychlorination zone, again in countercurrent. The role of the oxychlorination gas is to redisperse the metal crystallite particles, by the addition of chlorine.

For old regenerators, both calcination and oxychlorination gases were injected at the periphery of the annular zones, which generates a non-homogeneous velocity profile at the bottom of both the calcination and oxychlorination zones. Moreover, this particular mode of injection can cause a bad mixing of the calcination and oxychlorination gases, because of the poor radial mixing properties of catalytic moving beds. Some solutions were proposed to mix both gases outside the reactor by removing the calcination gas before the oxychlorination zone (Greenwood, 1987). Although some other technologies have recently been developed to have a better mixing between the two gases, such as different internal injection systems (Capelle et al., 2000), there is still a challenge to:

- correctly mix calcination and oxychlorination gases in order to reach the desired radial repartition of chlorine in the oxychlorination zone;

- avoid any disturbance in the downward catalyst flow;

- do all these steps inside the regenerator, for a minimum size of the whole device.

Both hydrodynamic and transport models are standardised ones, and can be developed easily. The model used for characterising the hydrodynamics, called a BrinkmanForchheimer model, is a modification of the laminar Navier-Stokes equations in order to take into account the friction between the liquid and the catalyst particles (Augier et al., 2008). These hydrodynamic equations are solved coupled with the transport equations of chemical species, which consider the radial dispersion of the components in the porous media (Peclet numbers are evaluated using the correlation of Guedes de Carvalho and Delgado, 2001).

Using this CFD model, a new internal was recently proposed to enhance the chlorine distribution in the oxychlorination zone (Fig. 16). A compact chamber was added between the oxychlorination and calcination zones, with an internal space located between two plates. A plurality of legs passes through the chamber to allow the downward movement of the catalyst. The calcination gas crosses the chamber using another series of tubes. The oxychlorination gas is introduced using an injection line in the internal space of the chamber, and orifices around the tubes enable the mixing of this oxychlorination gas with the calcination gas in the tubes, before their injection into the oxychlorination zone. A significant number of options is available to optimise this chamber: density of tubes and legs, means of injection of the mixing gas into the oxychlorination zone, size of the elements, position and size of the orifices, etc. The developed CFD model allows one to study:

- the behavior of the gases in the chamber (Fig. 17 of a hydrodynamic model); 

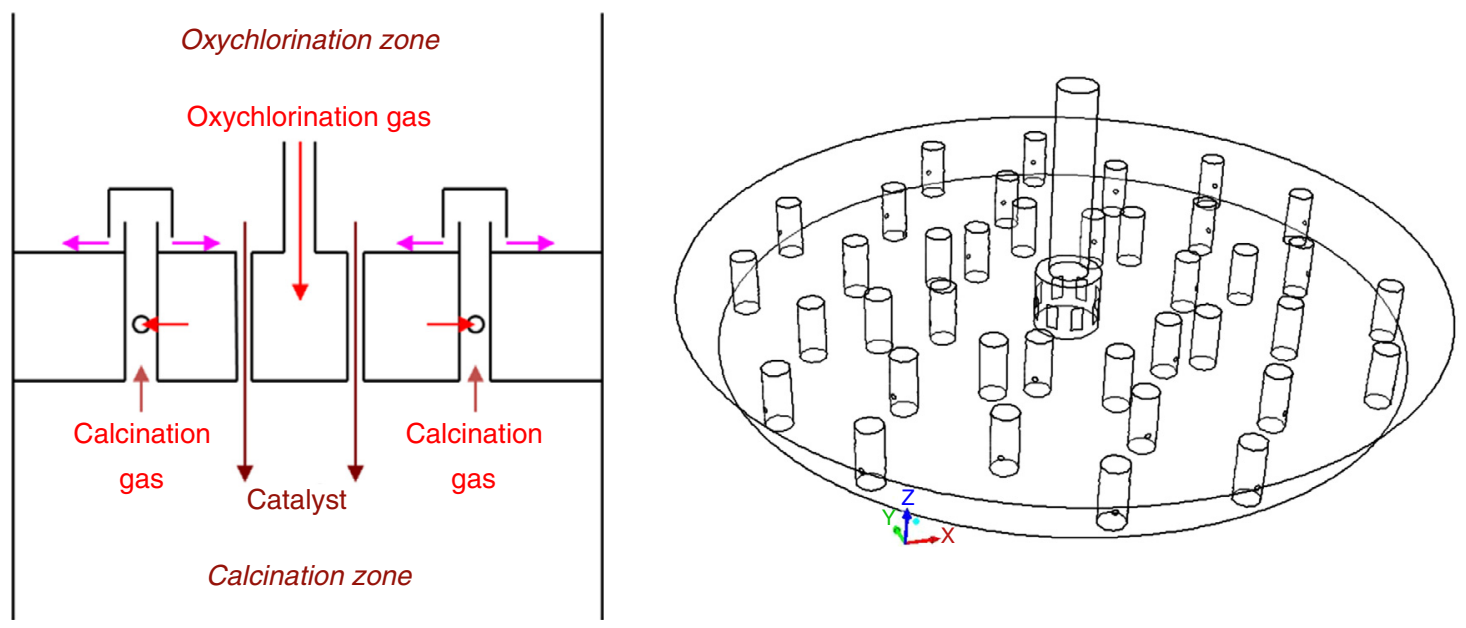

Figure 16

2D sketch and corresponding 3D view of the distributing device in the regenerating section of a catalytic reformer, Decoodt et al. (2014).

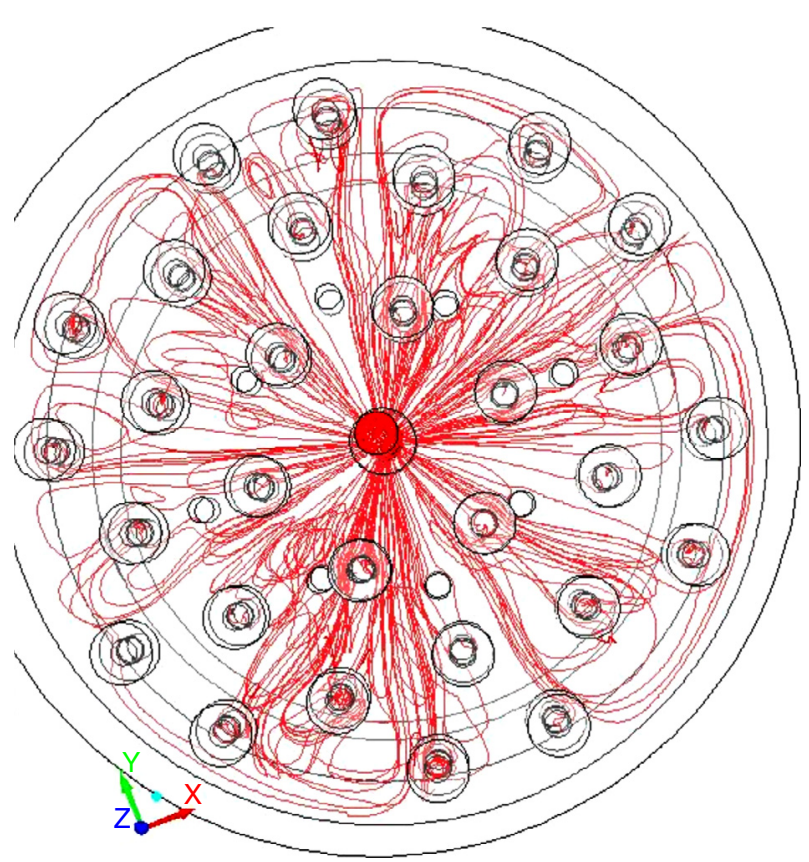

Figure 17

Top view of the streamlines of the oxychlorination gas entering the mixing chamber.

- the injection of the mixing gas into the oxychlorination bed and its radial dispersion above the internal (hydrodynamic and transport model using a chlorine tracer, Fig. 18).

As an example, the area of catalyst legs must be sufficiently large to prevent any fluidization of the catalyst in the legs, i.e. by reducing the local gas velocities in these legs,

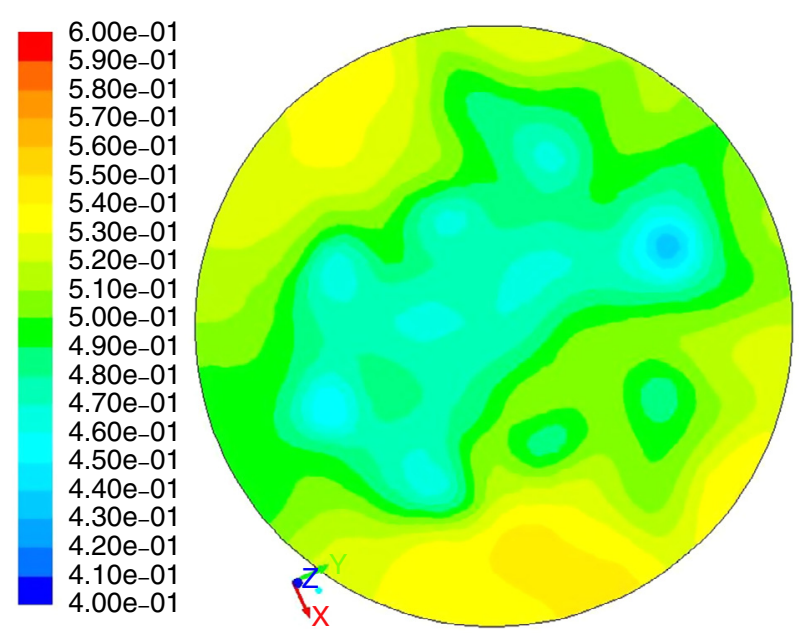

Figure 18

Chlorine concentration contours $10 \mathrm{~cm}$ above the mixing chamber, in the oxychlorination zone.

also considering that the bypass of calcination gas in the legs must be avoided by creating an adequate pressure drop. This modeling approach produced results for the optimization of this chamber in a few weeks. The choice of geometric parameters enables a perfect distribution of the oxychlorination gas streamlines in the chamber (Fig. 17), leading to an improved repartition of this gas in the mixing tubes $( \pm 1 \%$ difference in the flow rate). As a consequence, chlorine was quasi-equally distributed in the above oxychlorination bed, the small differences being due to the bypass of the calcination gas in the catalyst legs (Fig. 18). Other simulations have shown that a perfect distribution of chlorine 
( $\pm 1 \%$ difference of concentration) was reached only $30 \mathrm{~cm}$ above the chamber.

This new internal was recently implemented in several industrial units, greatly enhancing the radial temperature profiles in the oxychlorination bed, and extending the catalyst lifetime.

This clearly demonstrates the potential of CFD for the development of internals: these simple models generated remarkable results with an immediate impact in the industrial units, at a reasonable development cost.

\subsection{Internals for Hydrotreating Units}

As described in Section 1, hydrotreatment is required, first to end with products in compliance with quality specifications, and second because sulphur, nitrogen and metals act as poisons for most catalysts that will be used in processes downstream of the VDU. This operation takes place in high-pressure high-temperature reactors where there are multiple injections of hydrogen $\left(\mathrm{H}_{2}\right)$. The purpose of the latter injection is first to maintain the $\mathrm{H}_{2}$ partial pressure, and second to control the temperature profile and avoid excessively high temperature values inside the reactor that would damage the catalyst, hydrogenations being exothermic. The reactor section is thus divided into multiple beds with quench and distributing devices between them. These internals must be as efficient as possible in terms of flow and temperature homogeneity entering the following bed and be as compact as possible so that the catalyst volume inside the vessel is maximised.

CFD is used not only to perform technology screening but also to check and eventually adapt the preferred design to real industrial conditions which are impossible to reproduce by experiments.

\subsubsection{Quench Apparatus}

The quench box is one of the key internal elements of a hydroprocessing reactor. It is fixed between two beds and has a specific role for mixing the quench fluid (commonly cold hydrogen) and the hot reaction mixture. During the mixing process, the quench hydrogen should dissolve rapidly in the liquid phase through gas-liquid mixing in providing fresh hydrogen and lowering the temperature of the reaction mixture (Zhenyuan et al., 2013). CFD is today used more and more for the development of innovative quench box technologies. Recently, in the US patent 2014/ 0224707 by Haroun and Augier (2014), the inventors used a CFD Euler-Euler approach to develop new quench box technology. Figure 19 shows an illustration of CFD calculation in the quench box and the quench fluid injection system, respectively. The plots show the liquid guard shape on the quench pane and the gas-liquid stream lines in the quench

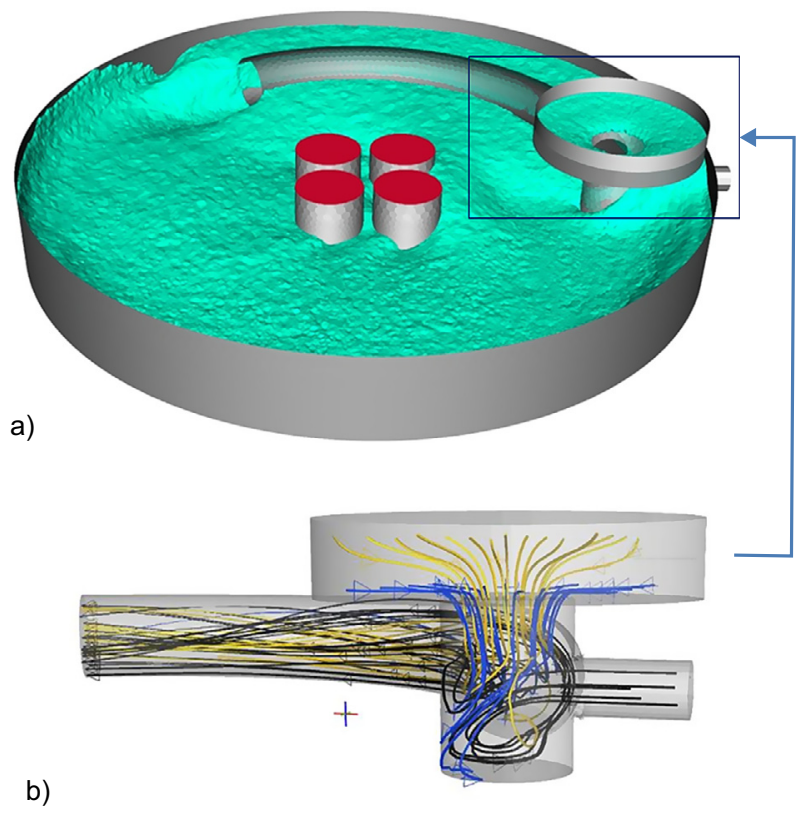

Figure 19

a) Liquid guard shape in the quench box system. b) Gas-liquid streamlines in the quench injection system. Liquid (blue), gas (yellow), quench fluid (black).

injection system obtained by CFD Euler-Euler simulations. The inventors show that the quench injection system plays an important role in the mixing efficiency. This study shows that CFD is a powerful tool that can be used to optimise or develop new quench box technologies.

\subsubsection{Gas-Liquid Flow Distributor}

Once the fluid phases have been cooled down and properly mixed, they must be redistributed to further react in the bed downstream, which is done via the use of distributing devices. Many distributors consist of a large number of chimneys or tubes through which vapour and liquid phases flow to further contact the catalyst below the distributor (Maiti and Nigam, 2007; Bazer-Bachi et al., 2013). For a long period of time, distributors were developed with no special attention to the vapour phase, considering that the main issue was to distribute the liquid phase. This was justified from common experiments, where no gas influence was indeed observed. However, many experiments are performed in ambient conditions and gas inertia effects are usually not well reproduced. Indeed, in HDT conditions, the liquid density can be as low as $550 \mathrm{~kg} \cdot \mathrm{m}^{-3}$, while vapour density can be as high $40 \mathrm{~kg} . \mathrm{m}^{-3}$. With according gas and liquid velocities only between air/water laboratory experiments and industrial conditions, the gas to liquid inertia ratio 

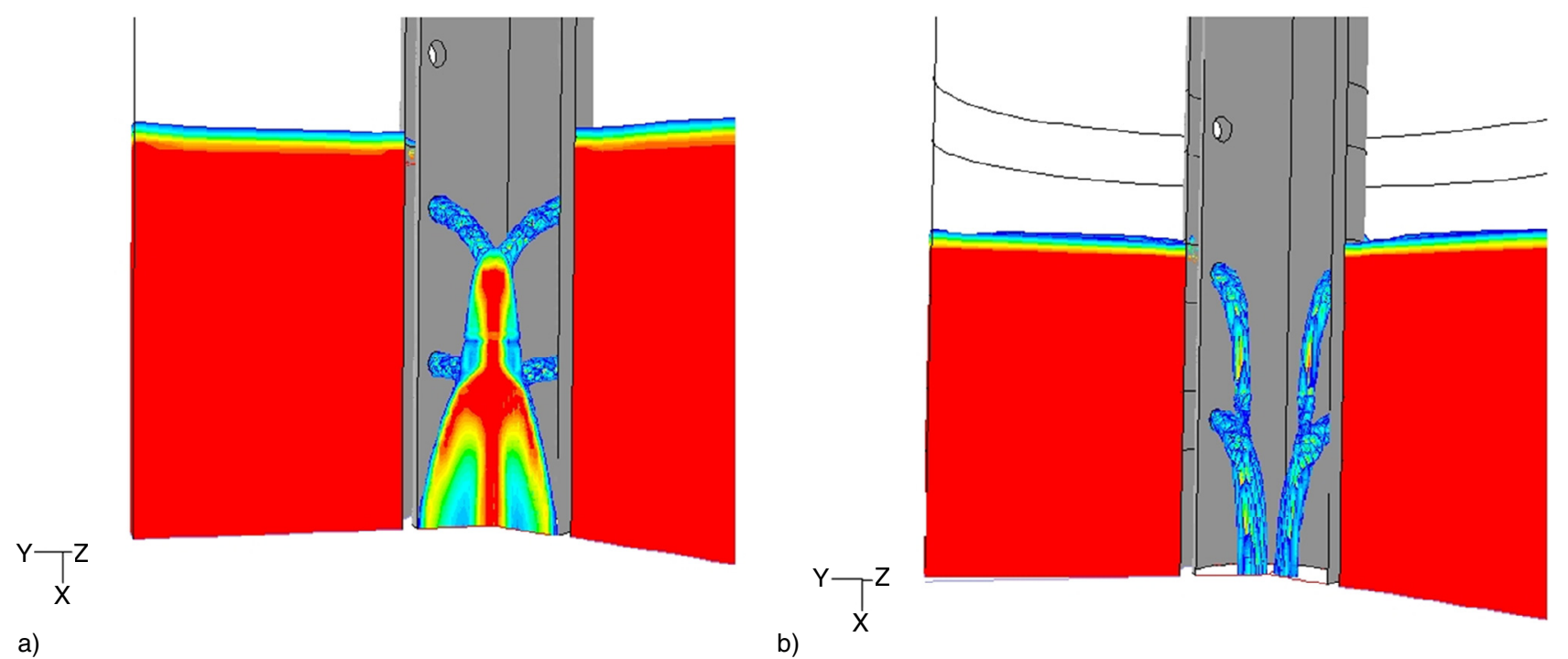

Figure 20

Liquid volume fraction contours of the flow through a HDT distribution tray for $V_{S L}=0.4 \mathrm{~cm} / \mathrm{s}$ and $V_{S G}=10 \mathrm{~cm} / \mathrm{s}$; a) with air and water; b) with industrial conditions physical properties (but for surface tension kept constant).

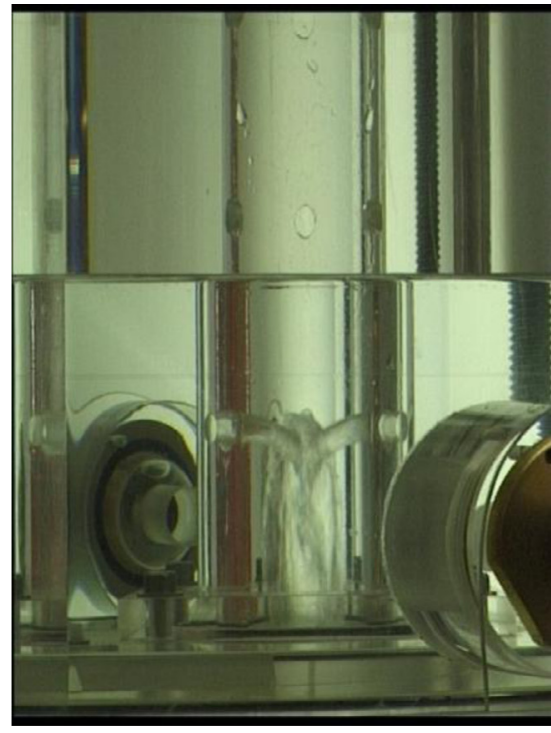

a)

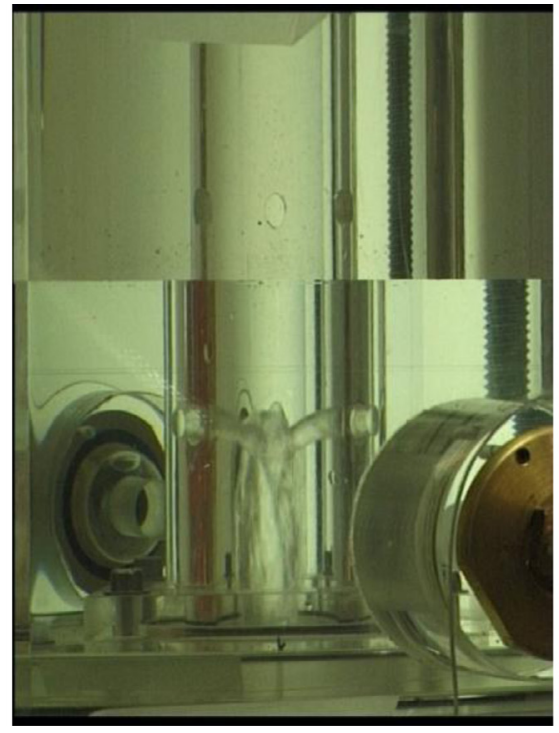

b)

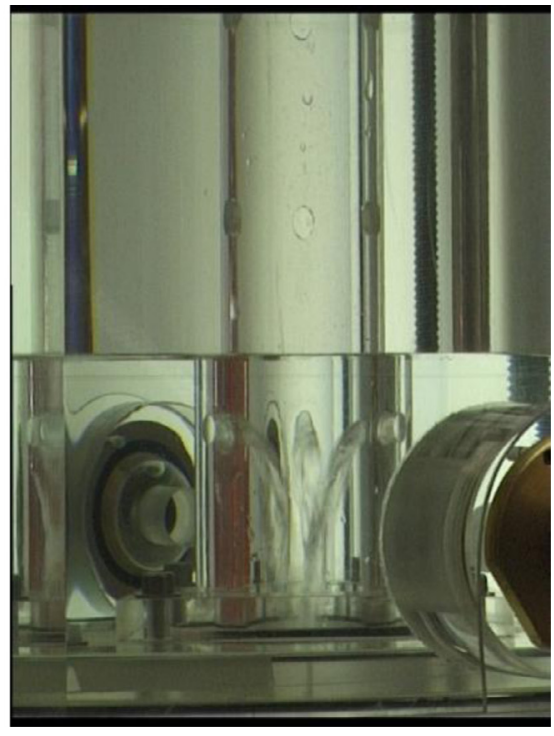

c)

Figure 21

Pictures of the flow through a HDT distribution tray for $V_{S L}=0.2 \mathrm{~cm} / \mathrm{s} ;$ a) $V_{S G}=0 \mathrm{~cm} / \mathrm{s} ;$ b) $V_{S G}=10 \mathrm{~cm} / \mathrm{s}$ with $\mathrm{N}_{2}$ in ambient conditions; c) $V_{S G}=10 \mathrm{~cm} / \mathrm{s}$ with $\mathrm{SF} 6$ at 3 bar.

would be underestimated by a factor of 60 in experiments. This has been shown by Raynal and Harter (2001), who observed a dramatic change in the flow inside the downcomer when changing from standard experimental to industrial conditions, which could affect the initial wetting performance in the catalyst bed downstream. Indeed, as can be seen in Figure 20, when real industrial conditions are considered, the liquid jets coming out from the orifices along the downcomer are deviated and may not interact themselves to form fine droplets as initially expected from 
experiments (for details on the flow configuration and simulation assumptions, Raynal and Harter, 2001). This effect was so important, that a dedicated experimental set-up has been built with the possibility of operating the unit reaching moderate pressure with high gas densities and using sulphur hexafluoride $\left(\mathrm{SF}_{6}\right)$, a gas 5 times heavier than air. As can be seen in Figure 21, what was experimentally observed corresponded to what had been obtained by CFD. Indeed, from Figure 21, which correspond to flow conditions with no gas or with air in ambient conditions, almost no differences are observed, while when operating with high-density gas closer to industrial conditions, one observes two main changes. First, the liquid jet shapes have been significantly modified, and second, the liquid level above the tray is found to be lower. The gas density being higher, the pressure drop across the tray is higher; then for a given pressure at the catalyst bed inlet, the pressure above the tray and on the liquid holdup is higher, resulting in a liquid level reduction for a constant liquid flow rate. Since the size, number and location of the orifices have to be determined to result in adequate liquid holdup on the tray, this gas influence clearly has to be taken into account in distributor design rules.

These examples show how CFD can be used to develop reactor internals, but one can easily understand how, from such results, one can develop intellectual property, which is of key importance for process licensors or technology vendors.

\section{CONCLUSION, PERSPECTIVES AND CHALLENGES}

This paper shows that CFD is a very useful tool to be considered during all the steps of process development. It can be used to prepare the development phase by helping design tools or by identifying critical parameters that should be considered during the development. It clearly completes experiments for developing a better knowledge of all complex phenomena that occur in chemical reactors, in particular for sensitivity analysis or extrapolation purposes, which are very difficult to address experimentally. CFD can also help in the design of equipment which is essential to ensure that industrial units match the design expectations. Many types of flows can be considered coupled with mass and heat transfer and with chemical reactions. Depending on their complexity, different levels of answers can be obtained, from qualitative trends to design rules. In all cases, CFD can provide solutions, which, even in cases where significant simplifications are required, should not be neglected, in particular when considering the low cost of CFD when compared with experiments, both in time and budget. Despite all these advantages, there are still challenges to address, as discussed below.

As mentioned in Section 1, 3D simulations are challenging and problems are often too complex with the present models.
Although simulations for single-phase flows or local simulations of two-phase flows with interface tracking can directly compete with experiments, this is not yet the case for multiphase systems with a Euler/Euler approach. Indeed, both experimental and numerical approaches complement each other. Experiments can provide information for closure law development, which can be used in simulations for extrapolation purposes. In that sense, there are still many types of complex flows for which interaction laws are not well understood and which deserve further research from the academic community. Moreover, too often mass and heat transfer, and also chemical reactions are not taken into account. This should be the main objective for the next decade to come.

Along with model developments, multi-scale approaches (Charpentier, 2009) and parallelisation will support the possibility of addressing more and more complex flows with less and less assumptions to make. Finally, it is believed that the use of simulation tools is still too complex and can only be handled by highly skilled people. In order to develop chemical reactor simulation skills, chemical engineering schools could either further integrate CFD in their educational programmes or develop closer relationships with mechanical engineering schools.

Combining all this, the authors believe that the use of CFD could be as popular in the oil and gas sector as it is in aeronautics and the automotive industry, and more importantly, it will help bring innovations to the market and make chemical reactors more and more efficient.

\section{REFERENCES}

Alvarez A., Ramirez S., Ancheyta J., Rodriguez L.M. (2007) Key role of reactor internal in hydroprocessing of oil fraction, Energy Fuels 21, 1731-1740.

Antos G.J., Aitani A.M. (2004) Catalytic Naphtha Reforming, Marcel Dekker, New York.

Attou A., Ferschneider G. (2000) A two-fluid hydrodynamic model for the transition between trickle an pulse flow in a cocurrent gas-liquid packed-bed reactor, Chem. Eng. Sci. 55, 491-511.

Augier F., Laroche C., Brehon E. (2008) Application of computational fluid dynamics to fixed bed adsorption calculations: Effect of hydrodynamics at laboratory and industrial scale, Separation and Purification Technology 63, 466-474.

Augier F., Idoux F., Delenne J.Y. (2010a) Numerical simulations of transfer and transport properties inside packed beds of spherical particles, Chem. Eng. Sci. 65, 3, 1055-1064.

Augier F., Koudil A., Royon-Lebeaud A., Muszynski L., Yanouri Q. (2010b) Numerical approach to predict wetting and catalyst efficiencies inside trickle bed reactors, Chem. Eng. Sci. 65, 1, 255-260.

Bazer-Bachi F., Augier F., Santos B. (2011) 1D and 2D simulations of partially wetted catalyst particles: A focus on heat transfer limitations, Chem. Eng. Sci. 66, 1953-1961.

Bazer-Bachi F., Haroun Y., Augier F., Boyer C. (2013) Experimental evaluation of distributor technologies for trickle-bed reactors, Ind. Eng. Chem. Res. 52, 11189-11197. 
Boisson N., Malin M.R. (1996) The numerical prediction of twophase flow in bubble columns, Int. J. Numerical Methods Fluids 23, 12, 1289-1310.

Boivin M., Simonin O., Squires K.D. (2000) On the prediction of gas-solid flows with two-way coupling using large eddy simulation, Phys. Fluids 12, 8, 2080-2090.

Boyer C., Koudil C., Chen P., Dudukovic M.P. (2005) Study of liquid spreading from a point source in a trickle-bed via gammaray tomography and CFD simulation, Chem. Eng. Sci. 60, 22, 6279-6288.

Braga M. (2013) Étude des phénomènes de transfert et de l'hydrodynamique dans des réacteurs agités à panier catalytique, $P h D D i s-$ sertation, Université Claude Bernard, Lyon, France.

Capelle M., Deves J.-M., Hoffmann F., Thery M. (2000) Process for regenerating a catalyst for the production of aromatic compounds or for reforming, with improved oxychlorination, US patent 6, 133, 183.

Chalermsinsuwan B., Piumsomboon P., Gidaspow D. (2009a) Kinetic theory based computation of PSRI riser: Part I-Estimate of mass transfer coefficient, Chem. Eng. Sci. 64, 6, 1195-1211.

Chalermsinsuwan B., Piumsomboon P., Gidaspow D. (2009b) Kinetic theory based computation of PSRI riser: Part II- Computation of mass transfer coefficient with chemical reaction, Chem. Eng. Sci. 64, 6, 1212-1222.

Charpentier J.-C. (2009) Perspective on multiscale methodology for product design and engineering, Comput. Chem. Eng. 33, 936-946.

Chen P., Dudukovic M.P., Sanyal J. (2005) Three-dimensional simulation of bubble column flows with coalescence and breakup, AIChE J. 51, 696-712.

Chen X., Closmann F., Rochelle G.T. (2011) Accurate screening of amines by the Wetted Wall Column, Energy Procedia 4, 101-108.

Cooper B.H., Donnis B.B.L., Moyse B. (1986) Oil Gas J. 8, December, 39-44.

Decoodt X., Plais C., Bazer-Bachi F. (2014) Continuous catalyst regeneration reactor with a chamber for mixing gas and distributing gas in the oxychlorination zone, US patent 2014/0027348.

Deen N.G., van Sint Annaland M., Van der Hoef M.A., Kuipers J. A.M. (2007) Review of discrete particle modeling of fluidized beds, Chem. Eng. Sci. 62, 1-2, 28-44.

Derouin C., Nevicato D., Forissier M., Wild G., Bernard J.R. (1997) Hydrodynamics of riser units and their impact on FCC operation, Ind. Eng. Chem. Res. 36, 4504-4515.

Dry M.E. (2002) The Fischer-Tropsch process: 1950-2000, Catal. Today 71, 227-241.

Forni L. (1997) Laboratory reactors, Catal. Today 34, 353-367.

Forret A., Schweitzer J.-M., Gauthier T., Krishna R., Schweich D. (2003) Influence of scale on the hydrodynamics of bubble column reactors: An experimental study in columns of $0.1,0.4$ and $1 \mathrm{~m}$ diameters, Chem. Eng. Sci. 58, 719-724.

Fourati M., Roig V., Raynal L. (2013) Liquid dispersion in packed columns: experiments and numerical modeling, Chem. Eng. Sci. 100, 266-278.

Gavi E., Marchisio D., Barresi A.A., Olsen M.G., Fox R.O. (2010) Turbulent precipitation in micromixers: CFD simulation and flow field validation, Chem. Eng. Res. Design 88, 9, 1182-1193.

Gidaspow D. (1994) Multiphase Flow and Fluidization: Continuum and Kinetic Theory Description, Academic Press, Boston.
Ginestra J.C., Jackson R. (1985) Pinning of a bed of particles in a vertical channel by a cross flow of gas, Ind. Eng. Chem. Fundam. 24, 121-128.

Greenwood A.R. (1987) Catalyst regeneration apparatus, US patent 4, 687, 637 .

Guedes de Carvalho J.R.F., Delgado J.M.P.Q. (2001) Radial dispersion in liquid flow through packed beds for $50<\mathrm{Sc}<750$ and $103<$ Pem $<105$, Fifth World Conference on Experimental Heat Transfer, Fluid Mechanics Thermodynamics.

Gupta R.K., Kumara V., Srivastava V.K. (2007) A new generic approach for the modeling of fluid catalytic cracking (FCC) riser reactor, Chem. Eng. Sci. 62, 4510-4528.

Haroun Y., Legendre D., Raynal L. (2010) Volume of fluid method for interfacial reactive mass transfer: Application to stable liquid film, Chem. Eng. Sci. 65, 10, 2896-2909.

Haroun Y., Augier F. (2014) Device for injecting and mixing fluids in a downward-flow reactor, US patent 2014/0224707.

Haroun Y., Raynal L. (2015) Use of Computational Fluid Dynamics for absorption packed column design, Oil Gas Sci. Technol. (this issue). DOI: $10.2516 /$ ogst/2015027.

Heidari A., Hashemabadi S.H. (2013) Numerical evaluation of the gas-liquid interfacial heat transfer in the trickle flow regime of packed beds at the micro and meso-scale, Chem. Eng. Sci. 104, $18,674-689$.

Hills J.H. (1974) Radial, non-uniformity of velocity and voidage in bubble column, Trans. Inst. Chem. Eng. 52, 1-9.

Hong H.-S., Cai Z.-J., Li J.-Q., Shi D.-S., Wan W.-Q., Li L. (2014) Simulation of gas-inducing reactor couples gas-liquid mass transfer and biochemical reaction, Biochemical Eng. J. 91, 1-9.

Horgue P., Augier F., Duru P., Quintard M., Prat M. (2013) Arrays of cylinders as an experimental and numerical laboratory for the study of trickling and pulsing flows, Chem. Eng. Sci. 102, 335-345.

Jiang J., Wu J., Zhang J., Poncin S., Li H.Z. (2014) Multiscale hydrodynamic investigation to intensify the biogas production in upflow anaerobic reactors, Bioresource Tech. 155, 1-7.

Jiradilok V., Gidaspow D., Damronglerd S., Koves W.J., Mostofi R. (2006) Kinetic theory based CFD simulation of turbulent fluidization of FCC particles in a riser, Chem. Eng. Sci. 61, 17, 5544-5559. Kataoka H., Takeuchi H., Nakao K., Yagi H., Tadaki T., Otake T. (1979) Mass transfer in a large bubble column, J. Chem. Eng. Japan 12, 2, 105-110.

Kirillov V.A., Mikhailova I.A., Fadeyev S.I., Korolev V.K. (2002) Critical phenomena of an exothermic reaction proceeding on a partially wetted porous catalyst grain, Combustion, Explosion and Shock Waves 38, 508-517.

Koide K., Morooka S., Ueyama K., Matsuura A., Yamashita F., Iwamoto S., Kato Y., Inoue H., Shigeta M., Suzuki S., Akehata T. (1979) Behavior of bubbles in large scale bubble column, J. Chem. Eng. Japan 12, 2, 98-104.

Kojima E., Unno H., Sato Y., Chida T., Imai H., Endo K., Inoue I., Kobayashi J., Kaji H., Nakanishi H., Yamamoto K. (1980) Liquid phase velocity in a $5.5 \mathrm{~m}$ diameter bubble column, J. Chem. Eng. Japan 13, 1, 16-21.

Krishna R., van Baten J.M., Ellenberger J., Higler A.P., Taylor R. (1999a) CFD simulations of sieve tray hydrodynamics, Chem. Eng. Res. Design 77, A7, 639-646.

Krishna R., Urseanu M.I., van Baten J.M., Ellenberger J. (1999b) Influence of scale on the hydrodynamics of bubble columns operating in churn-turbulent regime: experiments vs. Eulerian simulations, Chem. Eng. Sci. 54, 4903-4911. 
Krishna R., van Baten J.M., Urseanu M.I. (2000) Three-phase Eulerian simulations of bubble column reactors operating in the churn-turbulent regime: a scale up strategy, Chem. Eng. Sci. 55, 16, 3275-3286.

Krishna R., van Baten J.M. (2001) Eulerian simulations of bubble columns operating at elevated pressures in the churn turbulent flow regime, Chem. Eng. Sci. 56, 21-22, 6249-6258.

Krishna R., van Baten J.M. (2002) Scaling up bubble column reactors with highly viscous liquid phase, Chem. Eng. Tech. 25, 10, 1015-1020.

Krishna R., van Baten J.M. (2003) Modelling sieve tray hydraulics using computational fluid dynamics, Chem. Eng. Res. Design 81, A1, 27-38.

Kuipers J.A.M., van Swaaij W.P.M. (1997) Application of computational fluid dynamics to chemical reaction engineering, Rev. Chem. Eng. 13, 3, 1-118.

Lappalainen K., Manninen M., Alopaeus V. (2009) CFD modeling of radial spreading of flow in trickle-bed reactors due to mechanical and capillary dispersion, Chem. Eng. Sci. 64, 207-218.

Lappin A., Lübbert A. (1994) Numerical simulation of the dynamics of two-phase gas-liquid flows in bubble columns, Chem. Eng. Sci. 49, 21, 3661-3674

Larachi F., Desvigne D., Donnat L., Schweich D. (2006) Simulating the effects of liquid circulation in bubble columns with internals, Chem. Eng. Sci. 61, 4195-4206.

Larachi F., Hannaoui R., Horgue P., Augier F., Haroun Y., Youssef S., Rosenberg E., Prat M., Quintard M. (2014) X-ray microtomography and pore network modeling of single-phase fixed-bed reactors, Chem. Eng. J. 240, 290-306.

Li X., Yang N., Sun Y., Zhang L., Li X., Jiang B. (2014) Computational Fluid Dynamics Modeling of Hydrodynamics of a New Type of Fixed Valve Tray, Ind. Eng. Res. 53, 1, 379-389.

Lopes G.C., Rosa L.M., Mori M., Nunhez J.R., Martignoni W.P. (2011) Three-dimensional modeling of fluid catalytic cracking industrial riser flow and reactions, Comput. Chem. Eng. 35, 2159-2168.

Luo H., Svendsen H.F. (1996) Theoretical model for drop and bubble breakup in turbulent dispersions, AICHE J. 42, 5, 1225-1233.

Luo S.J., Fei W.Y., Song X.Y., Li H.Z. (2008) Effect of channel opening angle on the performance of structured packings, Chem. Eng. J. 144, 2, 227-234.

Luo X., Hartono A., Svendsen H.F. (2012) Comparative kinetics of carbon dioxide absorption in unloaded aqueous monoethanolamine solutions using wetted wall and string of discs columns, Chem. Eng. Sci. 82, 31-43.

Magnico P., Fongarland P. (2006) CFD simulations of two stirred tank reactors with stationary catalytic basket, Chem. Eng. Sci. 61, 1217-1236.

Mahoney J.A., Robinson K.K., Myers E.C. (1978) Catalyst evaluation with the gradientless reactor, Chemtech. 8, N12, 758-763.

Maiti R.N., Nigam K.D.P. (2007) Gas-Liquid distributors for trickle-bed reactors: A review, Ind. Eng. Chem. Res. 46, 6164-6182.

Marcandelli C., Lamine A.S., Bernard J.R., Wild G. (2000) Liquid distribution in trickle-bed reactor, Oil Gas Sci. Technol. 55, 407-415.

Mehmood N., Olmos E., Marchal P., Goergen J.-L., Delaunay S. (2010) Relation between pristinamycins production by Streptomyces pristinaespiralis, power dissipation and volumetric gas-liquid mass transfer coefficient, $k_{L} a$, Process Biochemistry 45, 11, 1779-1786.
Mitrovic M., Pitault I., Forissier M., Simoens S., Ronze D. (2005) Liquid-solid mass transfer in a three-phase stationary catalytic basket reactor, AIChE J. 51, 1747-1757.

Moula G., Nastoll W., Simonin O., Andreux R. (2013) Multiscale Study of Reactive Dense Fluidized Bed for FCC Regenerator, Oil Gas Sci. Technol. 68, 6, 1073-1092.

Neri A., Gidaspow D. (2000) Riser hydrodynamics: Simulation using kinetic theory, AIChE J. 46, 1, 52-67.

Ng K.M., Chu C.F. (1987) Trickle-Bed Reactors, Chem. Eng. Prog. 83, 11, 55-63.

Nijemeisland M., Dixon A.G. (2004) CFD study of fluid flow and wall heat transfer in a fixed bed of spheres, AIChE J. 50, 5, 906-921.

Olmos E., Gentric C., Vial C., Wild G., Midoux N. (2001) Numerical simulation of multiphase flow in bubble column reactors. Influence of bubble coalescence and break-up, Chem. Eng. Sci. 56, 21-22, 6359-6365.

Oryx GTL (2015) http://www.oryxgtl.com.qa/.

Perego C., Peratello S. (1999) Experimental methods in catalytic kinetics, Catal. Today 52, 133-145.

Petre C.F., Larachi F., Illiuta I., Grandjean B.P.A. (2003) Pressure drop through structured packings: breakdown into the contributing mechanisms by CFD modeling, Chem. Eng. Sci. 58, 163-177.

Pitault I., Fongarland P., Mitrovic M., Ronze D., Forissier M. (2004) Choice of laboratory scale reactors for HDT kinetic studies or catalyst tests, Catal. Today 98, 31-42.

Pitault I., Fongarland P., Koepke D., Mitrovic M., Ronze D., Forissier M. (2005) Gas-liquid and liquid-solid mass transfers in two types of stationary catalytic basket laboratory reactor, Chem. Eng. Sci. 60, 6240-6253.

Raynal L. (2001) Simulation numérique des colonnes à bulles, IFP Internal Report No. 56049.

Raynal L., Harter I. (2001) Studies of Gas-Liquid flow through distributing devices using VOF-CFD simulations, Chem. Eng. Sci. 56, 6385-6391.

Raynal L., Forret A., Schweitzer J.-M. (2001) Simulation numérique Euler/Euler de l'hydrodynamique de colonnes à bulles, in Récents progrès en Génie des Procédés, Lavoisier Tech. et Doc. Ed. 15, 227-234.

Raynal L. (2005) Use of CFD for applications in the oil and gas industry, Revue de la Houille Blanche 5, 75-78.

Raynal L., Gomez A., Caillat B., Haroun Y. (2013) $\mathrm{CO}_{2}$ Capture Cost Reduction: use of a Multiscale Simulations Strategy for a Multiscale Issue, Oil Gas Sci. Technol. 68, 6, 1093-1108.

Santos-Moreau V., Brunet-Errard L., Rolland M. (2012) Numerical CFD simulation of a batch stirred tank reactor with stationary catalytic basket, Chem. Eng. J. 207-208, 596-606.

Sanyal J., Marchisio D.L., Fox R.O., Dhanasekharan K. (2005) On the comparison between population balance models for CFD simulation of bubble columns, Ind. Eng. Chem. Res. 44, 14, 5063-5072.

Schweitzer J.-M. (2003) Personal communication.

Schwidder S., Schnitzlein K. (2012) A new model for the design and analysis of trickle bed reactors, Chem. Eng. J. 207-208, 758-765.

Sederman A.J., Gladden L.F. (2001) Magnetic resonance imaging as a quantitative probe of gas-liquid distribution and wetting efficiency in trickle-bed reactors, Chem. Eng. Sci. 56, 8, 2615-2628.

Servia A., Laloue N., Grandjean J., Rode S., Roizard C. (2014) Modeling of the $\mathrm{CO}_{2}$ Absorption in a Wetted Wall Column by Piperazine Solutions, Oil Gas Sci. Technol. 69, 5, 885-902. 
Solomenko Z., Haroun Y., Fourati M., Larachi F., Boyer C., Augier F. (2015) Liquid spreading in trickle-bed reactors: Experiments and numerical simulations using Eulerian-Eulerian two-fluid approach, Chem. Eng. Sci. 126, 698-710.

Spogis N., Nunhez J.R. (2009) Design of a High-Efficiency Hydrofoil Through the Use of Computational Fluid Dynamics and Multiobjective Optimization, AIChE J. 55, 7, 1723-1735.

Tosun G. (1984) A study of cocurrent downflow of nonfoaming gas-liquid systems in a packed bed. 2. Pressure drop: Search for a correlation, Ind. Eng. Chem. Process Des. Dev. 23, 35-39.

Trambouze P. (1993) Computational Fluid Dynamics applied to Chemical Reaction Engineering, Revue de l'Institut Français du Pétrole 48, 6, 595-613.

van Baten J.M., Krishna R. (2004) Eulerian simulation strategy for scaling up a bubble column slurry reactor for Fischer-Tropsch synthesis, Ind. Eng. Chem. Res. 43, 16, 4483-4493.

van der Hoef M.A., Annaland M.V., Kuipers J.A.M. (2004) Computational fluid dynamics for dense gas-solid fluidized beds: a multi-scale modeling strategy, Chem. Eng. Sci. 59, 22-23, 5157-5165.

van Houwelingen A.J., Kok S., Nicol W. (2010) Effectiveness Factors for Partially Wetted Catalysts, Ind. Eng. Chem. Res. 49, 17, 8114-8124.
Wang Y., Jinwen C., Larachi F. (2013) Modelling and simulation of trickle-bed reactors using computational fluid dynamics: a stateof-the-art review, The Canadian Journal of Chemical Engineering 91, 136-180.

Whitaker S. (1999) The method of volume averaging, theory and applications of transport in porous media, Kluwer Academic Publishers, Dordrecht, The Netherlands.

Zehner P. (1986) Momentum, mass and heat transfer in bubble columns. Part 1. Flow model of the bubble column and liquid velocities, Int. Chem. Eng. 26, 22.

Zhenyuan W., Zhenmin C., Zibin H., Kun Y. (2013) Intensified Gas-Liquid Mixing in a Quench Box under the Driving of Super gravitational Swirling Flow, Ind. Eng. Chem. Res. 52, 12802-12811.

Zou R. (1995) The packing of spheres in a cylindrical container: The thickness effect, Chem. Eng. Sci. 50, 9, 1504-1507.

Manuscript submitted in January 2015

Manuscript accepted in May 2015

Published online in August 2015

Cite this article as: L. Raynal, F. Augier, F. Bazer-Bachi, Y. Haroun and C. Pereira da Fonte (2015). CFD Applied to Process Development in the Oil and Gas Industry - A Review, Oil Gas Sci. Technol 71, 42. 